Research Article

\title{
HIS-Based Semiactive Suspension Dual-Frequency-Range Switching Control to Improve Ride Comfort and Antiroll Performance
}

\author{
Xiaojian Wu, ${ }^{1}$ Xiang Qiu, ${ }^{2}$ Bing Zhou ${ }^{(D)}{ }^{3}$ Juhua Huang, ${ }^{1}$ and Tingfang Zhang1 \\ ${ }^{1}$ School of Mechatronics Engineering, Nanchang University, Nanchang 330031, China \\ ${ }^{2}$ Center of Collaboration and Innovation, Jiangxi University of Technology, Nanchang 330098, China \\ ${ }^{3}$ State Key Laboratory of Advanced Design and Manufacturing for Vehicle Body, Hunan University, Changsha 410082, China
}

Correspondence should be addressed to Bing Zhou; zhou_bingo@163.com

Received 30 September 2018; Revised 13 March 2019; Accepted 8 April 2019; Published 12 May 2019

Academic Editor: Rui Moreira

Copyright (c) 2019 Xiaojian Wu et al. This is an open access article distributed under the Creative Commons Attribution License, which permits unrestricted use, distribution, and reproduction in any medium, provided the original work is properly cited.

The parameter sensitivity analysis of a hydraulically interconnected suspension (HIS) system shows that the sensitivity of the vibration responses in the bounce and roll modes to the hydraulic parameters are complementary. A novel HIS-based semiactive control method was thereby proposed to improve ride comfort and antiroll performance. In addition, the classic sky-hook maxmin damping switched strategy provides significant benefits around the body resonance, but otherwise performs similarly to, or sometimes even worse than, passive suspension. Therefore, a dual-frequency-range switching strategy, which has optimal maxmin damping in both frequency ranges, was developed for improving the ride comfort in a wider frequency bandwidth. In this study, a 9-DOF HIS system dynamics model was established, and the hydraulically interconnected subsystem model was validated experimentally. Subsequently, the elastic and damping characteristics of the hydraulically interconnected subsystem, as well as the parameter sensitivity in bounce mode and roll mode, were analyzed. Next, the sensitive parameters were optimized under sinusoidal excitation at various frequencies, and a frequency-range selector used to determine the excitation frequency range and adjust the shock absorber damping was designed. Finally, simulations in the frequency domain and time domain show that the proposed HIS-based semiactive dual-frequency-range switching control suspension improves the ride comfort in a wider frequency bandwidth and enhances the antiroll performance in the transient and steady steering process.

\section{Introduction}

A semiactive suspension system is characterized by low energy consumption, economical cost, and achieving the majority performance of the active suspension system within a certain frequency bandwidth. Thus far, a vast amount of academic and industrial research activities have been undertaken to study such systems [1-4].

As far as the research of semiactive suspensions is concerned, it can be summed up in two mainstream directions: the first focuses on developing advanced control strategies and algorithms, while the second revolves around developing reliable, high-performance adjustable shock absorbers (electrorheological, ER; magnetorheological dampers, MR) and emphatically analyzes the damping adjusting mechanism, delay response, and compensation control. In terms of the first of these directions, the most widely used classic control scheme, known as two-state sky-hook damping, is an on/off strategy that switches between high and low damping coefficients to improve ride comfort characterized by the body vertical acceleration [5]. Meanwhile, the road holding performance represented by wheel dynamic deformation is improved by developing a ground-hook control strategy [6]. A sky-hook and ground-hook combined control strategies were proposed by Ahmadian and Vahdati to take advantage of their respective benefits [7]. A hybrid sliding mode controller, including two separate model reference controllers designed to respectively force the plant to follow the ideal sky-hook and the ideal ground-hook models, was developed by Assadsangabi et al. [8] to enhance both ride comfort and road holding performance. In addition, some intelligent control algorithms, such as fuzzy, adaptive-fuzzy with Kalman filter [9], and 
neural networks [10] algorithms, were also applied to improve the performance of semiactive suspension in terms of ride comfort and road holding.

However, regardless of adjusting the damping coefficient by variable orifices, electrorheological fluids or magnetorheological fluids, the semiactive control suspension could improve only the antiroll performance during the transient steering process, but not the steady steering process. Furthermore, as the most widely applied control strategy, the sky-hook max-min damping switched method provides large benefits around the body resonance, but in other frequency ranges, it performs similarly to or sometimes even worse than passive suspension [11]. Therefore, studies on improving ride comfort in a wider frequency bandwidth and enhancing the antiroll performance during the transient and steady steering processes are a meaningful and challenging undertaking.

It is noted that research on hydraulically interconnected suspension (HIS) equipped with cross-connected hydraulic circuits and high-pressure accumulators is gradually becoming a hot topic. Swift et al. [12] designed a fluid inerter and established its mathematical model and analyzed the damping characteristics in various passive network layouts. Zhang et al. [13-15], Du et al. [16, 17], and Smith et al. [18, 19] have engaged in research on the antiroll of the HIS system, and they pointed out that the HIS system can effectively improve the antiroll performance without impacting the ride comfort. To improve the dynamic performance of different vibration modes, Yao et al. [20] proposed a dual-mode interconnected suspension that can be switched between two passive modes of roll-plane connected and pitch-plane connected. Based on the hydraulically interconnected architecture, Zhang et al. [15] proposed a switchable suspension system according to the motion-mode energy method. Wang et al. [21] developed a dual-mode switched suspension. Here, when the vehicle is traveling straight, the hydraulically interconnected inerter-springdamper mode is used to improve the ride comfort, and when the vehicle turns, the passive roll-plane interconnected mode is selected to improve the antiroll performance.

In our research, we found that the sensitivity of the vibration responses in the bounce mode and roll mode to the parameters of hydraulically interconnected subsystem is complementary, which provides an idea for developing a novel semiactive control to improve ride comfort and antiroll performance. Namely, we can adjust the two modes' sensitive parameters to improve the ride comfort and antiroll performance, respectively.

At the outset, it must be stressed that, because the development of a novel control theory is beyond the scope of this research, referring to the superiorities of the skyhook control strategy, this method is adopted to focus on the following: (1) to analyze parameter sensitivities for the bounce mode and roll mode, thereby developing a novel HIS-based semiactive control method and (2) to propose a switching control method based on excitation frequency-range identification, thereby improving the ride comfort in a wider frequency bandwidth.

The paper is organized as follows. In Section 2, a fullvehicle 9-DOF dynamics model and the "Pressure-Flow" equations for the hydraulically interconnected subsystem are established and validated by experimental tests. In Section 3, the parameter sensitivity analysis of a hydraulically interconnected subsystem is performed, and the dynamic characteristics in the bounce mode and roll mode are analyzed. On this basis, a novel HIS-based semiactive control method is proposed to improve ride comfort and antiroll performance. In Section 4, a HIS-based semiactive control strategy is designed using sky-hook algorithm, and a dual-frequencyrange switching control method based on approximately identifying excitation frequency-range is proposed. In Section 5 , the amplitude-frequency characteristic analyses of "body vertical acceleration-road excitation" for several semiactive control systems are compared, and numerical simulations including step input and the fishhook test are undertaken to illustrate the effectiveness of the developed approach. Finally, conclusions are summarized in Section 6.

\section{Dynamics Modeling and Experimental Verification}

2.1. 9-DOF Full-Vehicle Dynamics Modeling. As shown in Figure 1, based on the traditional suspension system, the HIS system adds a hydraulically interconnected subsystem plotted in Figure 2. Accordingly, a 9-DOF dynamics model, including body bounce motion, body roll motion, body pitch motion, unsprung mass vertical motion, lateral motion, and yaw motion, is established, as shown in the following equations (1)-(9):

Body bounce motion:

$$
m_{\mathrm{s}} \ddot{x}_{\mathrm{c}}=\sum_{j 0=\mathrm{fl}, \mathrm{fr}, \mathrm{rl}, \mathrm{rr}}\left[F_{j 0}-k_{j 0}\left(x_{s j 0}-x_{u j 0}\right)-c_{j 0}\left(\dot{x}_{s j 0}-\dot{x}_{\mathrm{u} j 0}\right)\right] \text {. }
$$

Body roll motion:

$$
\begin{aligned}
I_{\theta} \ddot{\theta}= & \left\{\begin{array}{l}
\sum_{j 1=\mathrm{fl}, \mathrm{rl}}\left[k_{j 1}\left(x_{\mathrm{s} j 1}-x_{\mathrm{u} j 1}\right)+c_{j 1}\left(\dot{x}_{s j 1}-\dot{x}_{\mathrm{u} j 1}\right)-F_{j 1}\right] \\
-\sum_{j 2=\mathrm{fr}, \mathrm{rr}}\left[k_{j 2}\left(x_{s j 2}-x_{\mathrm{u} j 2}\right)+c_{j 2}\left(\dot{x}_{s j 2}-\dot{x}_{\mathrm{u} j 2}\right)-F_{j 2}\right]
\end{array}\right\} \\
& \cdot \frac{b_{s}}{2}+M_{\theta} .
\end{aligned}
$$

Body pitch motion:

$$
I_{\varphi} \ddot{\varphi}=\left\{\begin{array}{c}
a \sum_{j 3=\mathrm{fr}, \mathrm{fl}}\left[k_{j 3}\left(x_{\mathrm{s} j 3}-x_{\mathrm{u} j 3}\right)+c_{j 3}\left(\dot{x}_{\mathrm{s} j 3}-\dot{x}_{\mathrm{u} j 3}\right)-F_{j 3}\right] \\
-b \sum_{j 4=\mathrm{rl}, \mathrm{rr}}\left[k_{j 4}\left(x_{s j 4}-x_{\mathrm{u} j 4}\right)+c_{j 4}\left(\dot{x}_{s j 4}-\dot{x}_{\mathrm{u} j 4}\right)-F_{j 4}\right]
\end{array}\right\} .
$$

Unsprung mass vertical motion:

$$
\begin{aligned}
m_{\mathrm{u} j 0} \ddot{x}_{\mathrm{u} j 0}= & k_{j 0}\left(x_{\mathrm{s} j 0}-x_{\mathrm{u} j 0}\right)+c_{j 0}\left(\dot{x}_{\mathrm{s} j 0}-\dot{x}_{\mathrm{u} j 0}\right) \\
& +k_{\mathrm{t} j 0}\left(x_{\mathrm{t} j 0}-x_{\mathrm{u} j 0}\right)-F_{j 0} .
\end{aligned}
$$




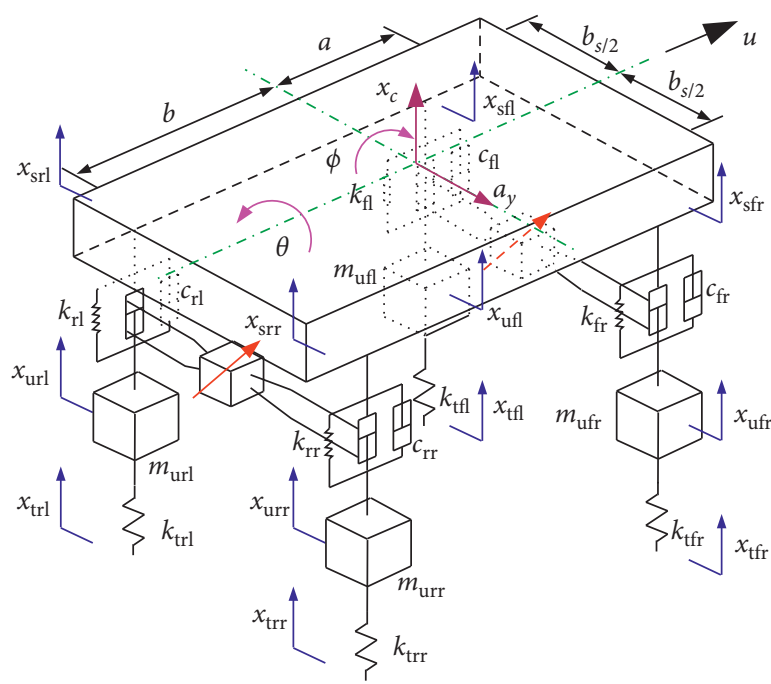

(a)

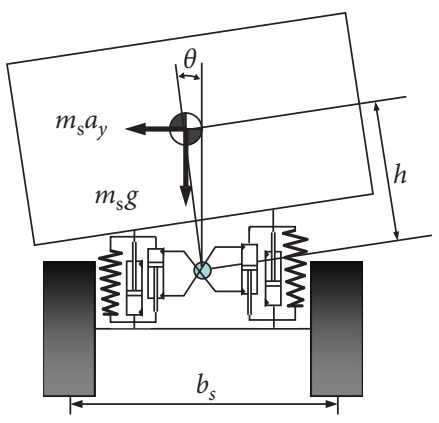

(b)

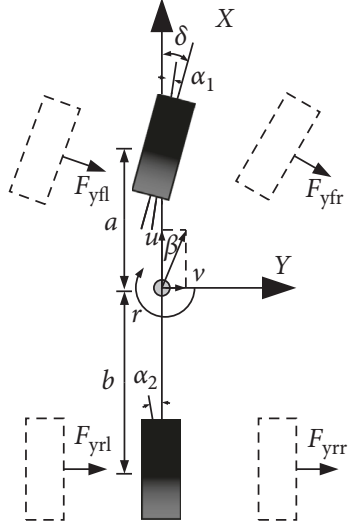

(c)

FIgURe 1: Vehicle dynamics model for the HIS system.

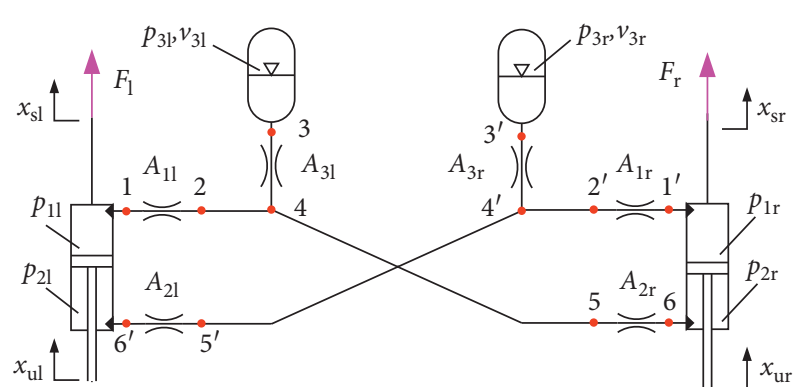

Figure 2: Hydraulically interconnected subsystem.

Yaw motion:

$I_{z} \dot{r}=a \sum_{j 3=\mathrm{fl}, \mathrm{fr}} F_{y j 3} \cos \delta-b \sum_{j 4=\mathrm{rl}, \mathrm{rr}} F_{y j 4}+\frac{b_{s}}{2}\left(F_{y \mathrm{fr}}-F_{y \mathrm{fl}}\right) \sin \delta$.

Lateral motion:

$$
m a_{y}=\sum_{j 3=\mathrm{fl}, \mathrm{fr} ; j 4=\mathrm{rl}, \mathrm{rr}}\left(F_{y j 3} \cos \delta+F_{y j 4}\right) .
$$

Roll moment:

$$
\begin{aligned}
& M_{\theta}=m_{\mathrm{s}} a_{y} h+m_{\mathrm{s}} g h \theta, \\
& a_{y}=\dot{v}+u r,
\end{aligned}
$$

$$
\left\{\begin{array}{l}
x_{\mathrm{sfl}}=x_{\mathrm{c}}-\frac{b_{s}}{2} \theta+a \varphi, \\
x_{\mathrm{sfr}}=x_{\mathrm{c}}+\frac{b_{s}}{2} \theta+a \varphi, \\
x_{\mathrm{srl}}=x_{\mathrm{c}}-\frac{b_{s}}{2} \theta-b \varphi, \\
x_{\mathrm{srr}}=x_{\mathrm{c}}+\frac{b_{s}}{2} \theta-b \varphi,
\end{array}\right.
$$

where $j$ is equal to $\mathrm{fl}$, $\mathrm{fr}, \mathrm{fr}$, and $\mathrm{rr}$, and the subscripts $\mathrm{fl}$, $\mathrm{fr}$, $\mathrm{fr}$, and rr represent the front left, front right, rear left, and rear right sides, respectively. $m$ is the vehicle mass. $m_{\mathrm{s}}$ and $m_{\mathrm{u} j}$ represent the sprung mass and the unsprung mass. $x_{\mathrm{c}}$ is the displacement at the center of gravity of the body. $\theta$ and $\varphi$ are the body roll angle and pitch angle, respectively. $x_{\mathrm{s} j}$ and $x_{\mathrm{u} j}$ are the displacements of the sprung mass and the unsprung mass. $x_{\mathrm{t} j}$ is the road excitation. $I_{\theta}, I_{\varphi}$, and $I_{z}$ are roll moment of inertia, pitch moment of inertia, and yaw moment of inertia, respectively. $a$ and $b$ are the distances from vehicle's center of gravity to the front and rear axles, respectively. $b_{s}$ is the track width. $h$ is the height of the sprung mass center of gravity from the roll center. $k_{j}$ is the spring stiffness. $c_{j}$ is the damping coefficient. $k_{\mathrm{t} j}$ is the tire vertical stiffness. $r$ is the yaw rate, $u$ is the vehicle longitudinal velocity, and $v$ is the lateral velocity. $\delta$ is the wheel steering angle. $a_{y}$ is the vehicle lateral acceleration. $F_{y j}$ is the wheel lateral force, which can be calculated by the tire model. $F_{j}$ is the vertical force generated by the hydraulic interconnection subsystem, which is expressed as equation (27).

Note that the body vertical acceleration $\ddot{x}_{c}$ and body roll angle $\theta$ are usually used as indicators of ride comfort and antiroll performance, respectively, as well as wheel dynamic deformation $x_{\mathrm{u} j 0}-x_{\mathrm{t} j 0}$ is adopted to reflect road holding performance.

2.2. Tire Model. The Magic formula tire model is adopted in this study to reflect the coupling relationship between the vertical load and lateral force as follows:

$$
F_{y}=D \sin \{C \arctan [B x-E(B x-\arctan B x)]\},
$$

where $x$ is the tire slip angle, $B$ is the stiffness factor, $C$ is the shape factor, $D$ is the peak factor, and $E$ is the curvature factor. $B, D$, and $E$, relating with the wheel load $F_{z}$, which is calculated by $F_{z j 3}=0.5 b m g /(a+b)+k_{\mathrm{t} j 3}\left(x_{0 j 3}-x_{\mathrm{uj} 3}\right)$ and $F_{z j 4}=0.5 a m g /(a+b)+k_{\mathrm{t} j 4}\left(x_{0 j 4}-x_{\mathrm{u} j 4}\right)$, can be expressed as follows: 


$$
\left\{\begin{array}{l}
D=a_{1} F_{z}^{2}+a_{2} F_{z}, \\
E=a_{6} F_{z}^{2}+a_{7} F_{z}+a_{8}, \\
B=B_{1} /(C \times D), \\
B_{1}=a_{3} \sin \left(a_{4} \times \arctan \left(a_{5} \times F_{z}\right)\right) .
\end{array}\right.
$$

The values of parameters $a_{1}-a_{8}$ are listed in Table 1 .

2.3. Hydraulically Interconnected Subsystem Modeling. As shown in Figure 2, for the hydraulically interconnected subsystem, the chambers of the left and right hydraulic cylinders are cross-connected by hydraulic circuits, and two accumulators with a certain pressure are linked in the hydraulic circuits. Taking the hydraulic circuit "1-2-3-4-5-6" plotted in Figure 2 as an example, the "Pressure-Flow" model of the hydraulically interconnected subsystem is established as follows.

Ignoring friction loss in the pipeline, it can be derived that $p_{2}=p_{4}=p_{5}, p_{2^{\prime}}=p_{4^{\prime}}=p_{5^{\prime}}, p_{1}=p_{11}, p_{6^{\prime}}=p_{21}, p_{1^{\prime}}=$ $p_{1 \mathrm{r}}, p_{6}=p_{2 \mathrm{r}}$, and $p_{3}=p_{31}$, and $p_{3^{\prime}}=p_{3 \mathrm{r}}$. Here, the subscripted numbers correspond to the position of the markers in Figure 2.

(1) The "Pressure-Displacement" relationship in the accumulator:

$$
\left\{\begin{array}{l}
\Delta v_{31}=A_{2}\left(x_{\mathrm{sr}}-x_{\mathrm{ur}}\right)-A_{1}\left(x_{\mathrm{sl}}-x_{\mathrm{ul}}\right), \\
\Delta v_{3 \mathrm{r}}=A_{2}\left(x_{\mathrm{sl}}-x_{\mathrm{ul}}\right)-A_{1}\left(x_{\mathrm{sr}}-x_{\mathrm{ur}}\right), \\
Q_{31}=A_{2}\left(\dot{x}_{\mathrm{sr}}-\dot{x}_{\mathrm{ur}}\right)-A_{1}\left(\dot{x}_{\mathrm{sl}}-\dot{x}_{\mathrm{ul}}\right), \\
Q_{3 \mathrm{r}}=A_{2}\left(\dot{x}_{\mathrm{sl}}-\dot{x}_{\mathrm{ul}}\right)-A_{1}\left(\dot{x}_{\mathrm{sr}}-\dot{x}_{\mathrm{ur}}\right),
\end{array}\right.
$$

where $\Delta v_{31}$ and $\Delta v_{3 \mathrm{r}}$ are the volume that flows in or out of the liquid chamber of the left and right accumulators, respectively. $A_{1}$ and $A_{2}$ are the liquid action areas of the rod chamber and the rodless chamber, respectively.

The instantaneous pressure of gas in the accumulator is derived assuming the polytropic process of the gas as follows:

$$
p_{0} v_{0}^{n}=p_{31} v_{31}^{n}
$$

where $n$ is the polytropic exponent of gas which is usually between 1.2 and 1.4 [23], $v_{31}$ is the gas volume in the gas chamber of the accumulator, and $v_{0}$ and $p_{0}$ are the initial gas volume and pressure in the accumulator, respectively.

Combining (12) and (13) yields the following equation:

$$
\begin{aligned}
& p_{31}=p_{0}\left(\frac{v_{0}}{v_{0}-\Delta v_{31}}\right)^{n}, \\
& p_{3 \mathrm{r}}=p_{0}\left(\frac{v_{0}}{v_{0}-\Delta v_{3 \mathrm{r}}}\right)^{n} .
\end{aligned}
$$

(2) The relationship between throttle valve flow and pressure in segment " $1-2$ " is given by
TABLE 1: Magic formula tire model parameters [22].

\begin{tabular}{ccccccccc}
\hline$a_{1}$ & $a_{2}$ & $a_{3}$ & $a_{4}$ & $a_{5}$ & $a_{6}$ & $a_{7}$ & $a_{8}$ & $C$ \\
\hline-22.1 & 1011 & 1078 & 1.82 & 0.208 & 0 & -0.35 & 0.707 & 1.3 \\
\hline & $Q_{12}=c_{\mathrm{d}} A_{11} \sqrt{\frac{2\left|\Delta p_{12}\right|}{\rho}} \operatorname{sgn}\left(\Delta p_{12}\right)=-A_{1}\left(\dot{x}_{\mathrm{sl}}-\dot{x}_{\mathrm{ul}}\right)$,
\end{tabular}

where sgn represents the signum function.

It can be rewritten as follows:

$$
p_{11}=p_{2}+\frac{\rho}{2}\left[\frac{A_{1}\left(\dot{x}_{\mathrm{sl}}-\dot{x}_{\mathrm{ul}}\right)}{c_{\mathrm{d}} A_{11}}\right]^{2} \operatorname{sgn}\left(Q_{12}\right) \text {. }
$$

(3) The relationship between throttle valve flow and pressure in segment " $3-4$ " is given by

$$
Q_{34}=c_{\mathrm{d}} A_{31} \sqrt{\frac{2\left|\Delta p_{34}\right|}{\rho}} \operatorname{sgn}\left(\Delta p_{34}\right)=-Q_{31}
$$

Deriving $p_{4}$ as

$$
p_{4}=p_{3}-\frac{\rho}{2}\left[\frac{Q_{31}}{c_{\mathrm{d}} A_{31}}\right]^{2} \operatorname{sgn}\left(-Q_{31}\right) \text {. }
$$

(4) The relationship between throttle valve flow and pressure in segment " $5-6$ " is given by

$Q_{56}=c_{\mathrm{d}} A_{2 \mathrm{r}} \sqrt{\frac{2\left|\Delta p_{56}\right|}{\rho}} \operatorname{sgn}\left(\Delta p_{56}\right)=-A_{2}\left(\dot{x}_{\mathrm{sr}}-\dot{x}_{\mathrm{ur}}\right)$.

Therefore,

$$
p_{6}=p_{5}-\frac{\rho}{2}\left[\frac{Q_{56}}{c_{\mathrm{d}} A_{2 \mathrm{r}}}\right]^{2} \operatorname{sgn}\left(Q_{56}\right) .
$$

The final expressions of pressure become as follows:

$$
\begin{aligned}
p_{1 \mathrm{l}}= & p_{3 \mathrm{l}}+\frac{\rho}{2}\left(\frac{Q_{31}}{c_{\mathrm{d}} A_{31}}\right)^{2} \operatorname{sgn}\left(Q_{31}\right) \\
& -\frac{\rho}{2}\left[\frac{A_{1}\left(\dot{x}_{\mathrm{sl}}-\dot{x}_{\mathrm{ul}}\right)}{c_{\mathrm{d}} A_{11}}\right]^{2} \operatorname{sgn}\left(A_{1}\left(\dot{x}_{\mathrm{sl}}-\dot{x}_{\mathrm{ul}}\right)\right), \\
p_{2 \mathrm{l}}= & p_{3 \mathrm{r}}+\frac{\rho}{2}\left(\frac{Q_{3 \mathrm{r}}}{c_{\mathrm{d}} A_{3 \mathrm{r}}}\right)^{2} \operatorname{sgn}\left(Q_{3 \mathrm{r}}\right) \\
& +\frac{\rho}{2}\left[\frac{A_{2}\left(\dot{x}_{\mathrm{sl}}-\dot{x}_{\mathrm{ul}}\right)}{c_{\mathrm{d}} A_{2 \mathrm{l}}}\right]^{2} \operatorname{sgn}\left(A_{2}\left(\dot{x}_{\mathrm{sl}}-\dot{x}_{\mathrm{ul}}\right)\right), \\
p_{1 \mathrm{r}}= & p_{3 \mathrm{r}}+\frac{\rho}{2\left(\frac{Q_{3 \mathrm{r}}}{c_{\mathrm{d}} A_{3 \mathrm{r}}}\right)^{2} \operatorname{sgn}\left(Q_{3 \mathrm{r}}\right)} \\
& -\frac{\rho}{2}\left[\frac{A_{1}\left(\dot{x}_{\mathrm{sr}}-\dot{x}_{\mathrm{ur}}\right)}{c_{\mathrm{d}} A_{1 \mathrm{r}}}\right]^{2} \operatorname{sgn}\left(A_{1}\left(\dot{x}_{\mathrm{sr}}-\dot{x}_{\mathrm{ur}}\right)\right),
\end{aligned}
$$




$$
\begin{aligned}
p_{2 \mathrm{r}}= & p_{31}+\frac{\rho}{2}\left(\frac{Q_{31}}{c_{\mathrm{d}} A_{31}}\right)^{2} \operatorname{sgn}\left(Q_{31}\right) \\
& +\frac{\rho}{2}\left[\frac{A_{2}\left(\dot{x}_{\mathrm{sr}}-\dot{x}_{\mathrm{ur}}\right)}{c_{\mathrm{d}} A_{2 \mathrm{r}}}\right]^{2} \operatorname{sgn}\left(A_{2}\left(\dot{x}_{\mathrm{sr}}-\dot{x}_{\mathrm{ur}}\right)\right),
\end{aligned}
$$

where $c_{\mathrm{d}}$ is the discharge coefficient and $\rho$ is the fluid density. $A_{11}, A_{21}, A_{1 \mathrm{r}}, A_{2 \mathrm{r}}, A_{3 \mathrm{l}}$, and $A_{3 \mathrm{r}}$ are the flow areas of throttle valves.

Based on equations (21)-(24), it can be determined that the hydraulically interconnected subsystem consists of the elastic system and damping system. The elastic force comes from the accumulator, and the damping force is caused by the throttle valve. Taking the left side as an example, the elastic force can be calculated by

$$
F_{1 \_k}=\left(p_{31}-p_{0}\right) A_{1}-\left(p_{3 \mathrm{r}}-p_{0}\right) A_{2} .
$$

The damping force can be computed by

$$
F_{1 \_c}=\left(p_{11}-p_{31}\right) A_{1}-\left(p_{21}-p_{3 \mathrm{r}}\right) A_{2} \text {. }
$$

The vertical forces generated by the hydraulic interconnection subsystem shown in Figure 2 are derived to be as follows:

$$
\left\{\begin{array}{l}
F_{1}=\left(p_{11}-p_{0}\right) A_{1}-\left(p_{21}-p_{0}\right) A_{2} \\
F_{\mathrm{r}}=\left(p_{1 \mathrm{r}}-p_{0}\right) A_{1}-\left(p_{2 \mathrm{r}}-p_{0}\right) A_{2}
\end{array}\right.
$$

2.4. Experimental Verification for Hydraulically Interconnected Subsystem. A test bench used to validate the established hydraulically interconnected subsystem dynamics model is shown in Figure 3. In the experimental test scheme, the hydraulic cylinder base is fixed, and the sinusoidal displacement excitations are loaded on the hydraulic rods by actuators. Subsequently, sensors measure the displacements, and actuator forces with a sampling frequency of $102.4 \mathrm{~Hz}$. In Figures $4(\mathrm{a})-4(\mathrm{c})$, a pair of sinusoidal excitations with the same phase, a magnitude of $30 \mathrm{~mm}$, and a period of 2 seconds were applied to perform a bounce motion. Meanwhile, in Figures $4(\mathrm{~d})-4(\mathrm{f})$, the sinusoidal excitations are changed to a phase difference of $180^{\circ}$ to simulate a roll motion.

It can be seen from Figure 4 that, although there are errors between the simulated and the experimental curves that may be caused by the run-in period of hydraulic cylinders, the trend and the main characteristics of the curves are consistent. Therefore, the established dynamic model has the potential to describe the characteristics of the hydraulically interconnected subsystem.

\section{Parameter Sensitivity Analysis}

Understanding the effect of each throttle damping on the vibration response in bounce and roll modes is an important basis for the optimization of HIS and the development of semiactive control. We thereby analyzed the sensitivity of hydraulically interconnected subsystem parameters including damping coefficient of throttle valves and precharge

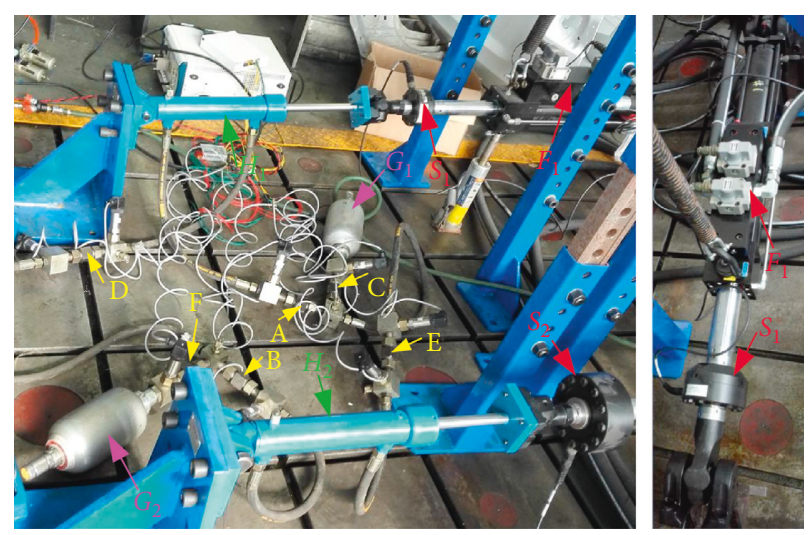

FIGURE 3: Test bench for the hydraulically interconnected subsystem. A-F: throttle valves; $G_{1}, G_{2}$ : accumulators; $H_{1}, H_{2}$ : hydraulic cylinders; $S_{1}, S_{2}$ : displacement sensors; and $F_{1}, F_{2}$ : actuation cylinders.

pressure in accumulators, adopting the experimental design method of parameter study in Isight software. The parameter interval for sensitivity analysis and the vibration response function under the two modes are listed in Table 2.

Assume that the throttle valve flow aperture is a regular round hole. Given that the damping coefficient of throttle valve depends on the flow cross-sectional area, the parameter of damping coefficient of throttle valve can be replaced by flow diameter. With consideration of the symmetrical arrangement of the hydraulically interconnected system, we use the left-side parameters of the hydraulically interconnected subsystem as representative to illustrate the experimental test scheme and analyze sensitivity results.

The following conclusions can be drawn from the Pareto charts, and the main effect graph is illustrated in Figures 5-7:

(1) In the bounce mode, the body vertical acceleration is sensitive to the flow aperture of the throttle valve connecting to the hydraulic cylinder, but insensitive to the accumulator precharge pressure and flow aperture of the throttle valve connecting to the accumulator.

(2) In the roll mode, the roll vibration is sensitive to the flow aperture of the throttle valve connecting to the accumulator, but insensitive to the rest of the parameters.

It is interesting to note that the sensitivity of the ride comfort and the antiroll performance of the vehicle equipped with the HIS system to the hydraulic system parameters are exactly complementary.

(3) Although the vibration responses in the two modes are insensitive to precharge pressure in accumulators, it can be found from Figure 7 that, as the precharge pressure increases, the root mean square (RMS) of the roll angle is effectively reduced.

In addition, according to equations (25) and (26), the curves of elastic and damping characteristics of the hydraulically interconnected subsystem in the two modes are obtained in Figure 8. 


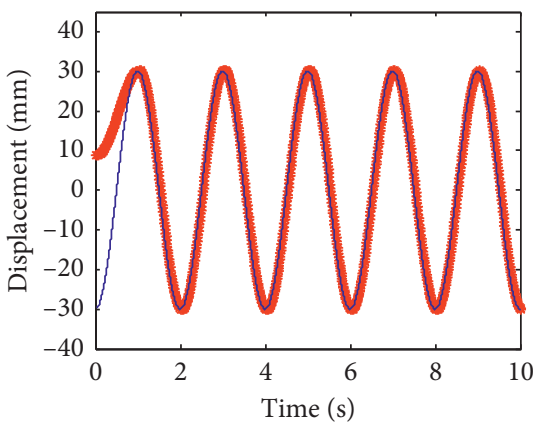

*- Experimental test - Simulation

(a)

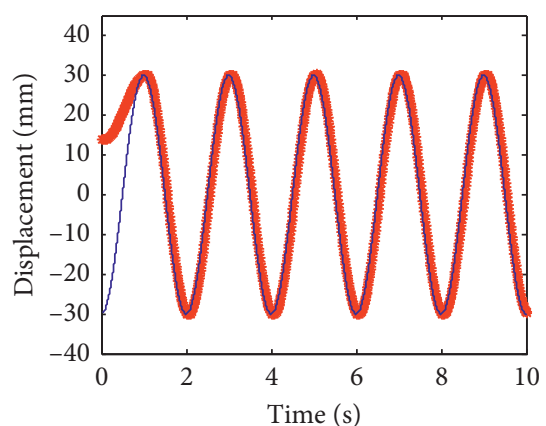

*- Experimental test

- Simulation

$(\mathrm{d})$

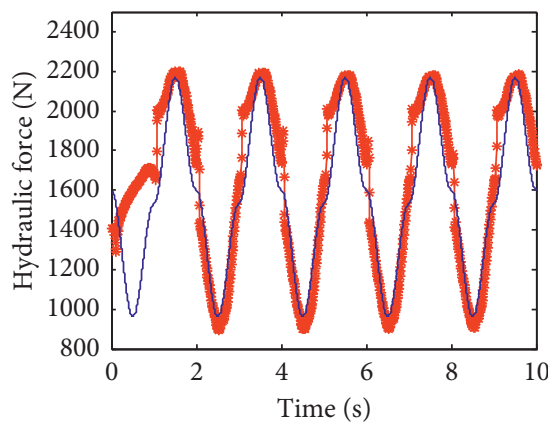

*- Experimental test - Simulation

(b)

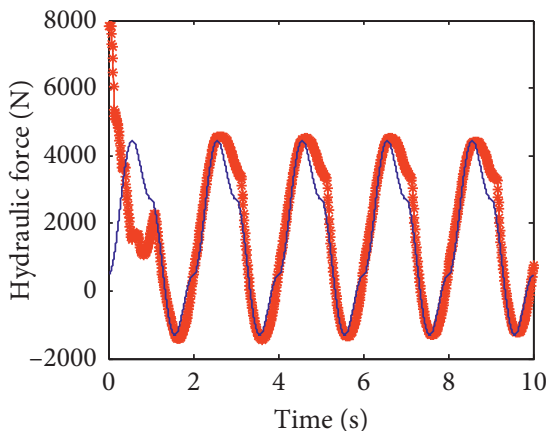

*- Experimental test

- Simulation

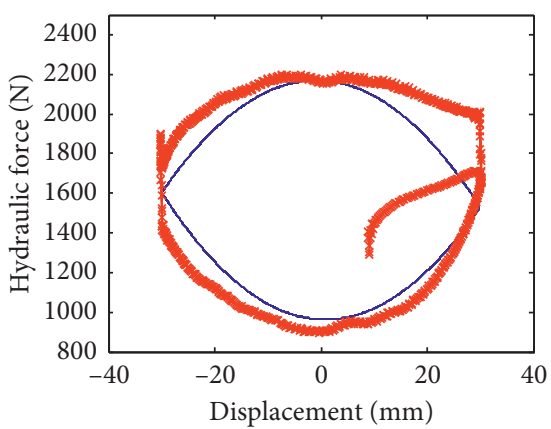

$\rightarrow$ Experimental test

_ Simulation

(c)

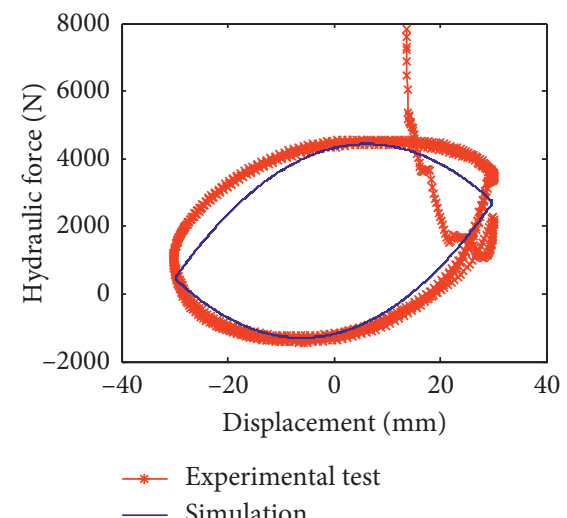

(f)

FIgURE 4: Comparisons between simulation and experimental test. (a) Sinusoidal displacement excitation for bounce modal. (b) Hydraulic force for bounce modal. (c) Indicator diagram for bounce modal. (d) Sinusoidal displacement excitation for roll modal. (e) Hydraulic force for roll modal. (f) Indicator diagram for roll modal.

TABLE 2: Experimental test scheme for sensitivity analysis.

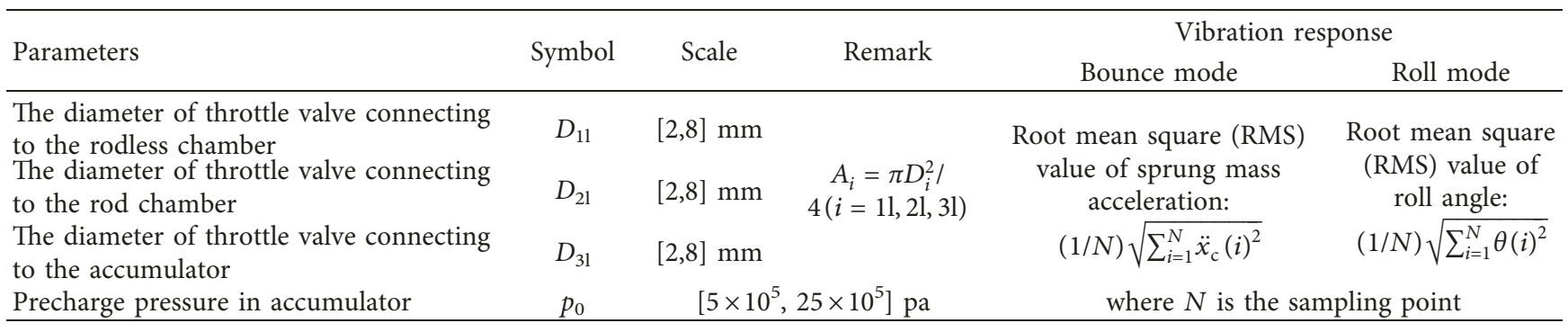

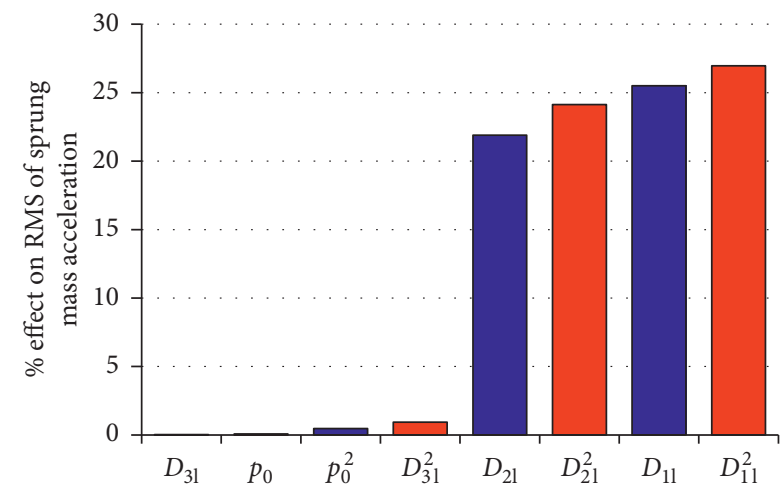

FIGURE 5: Pareto chart in the bounce mode.

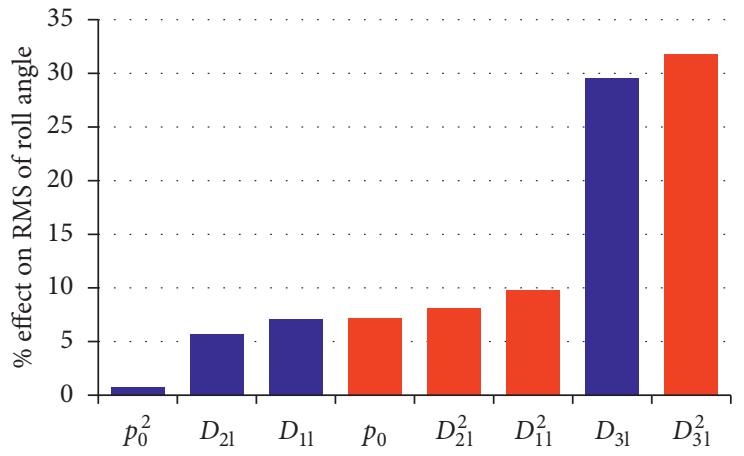

FIgURE 6: Pareto chart in the roll mode. 


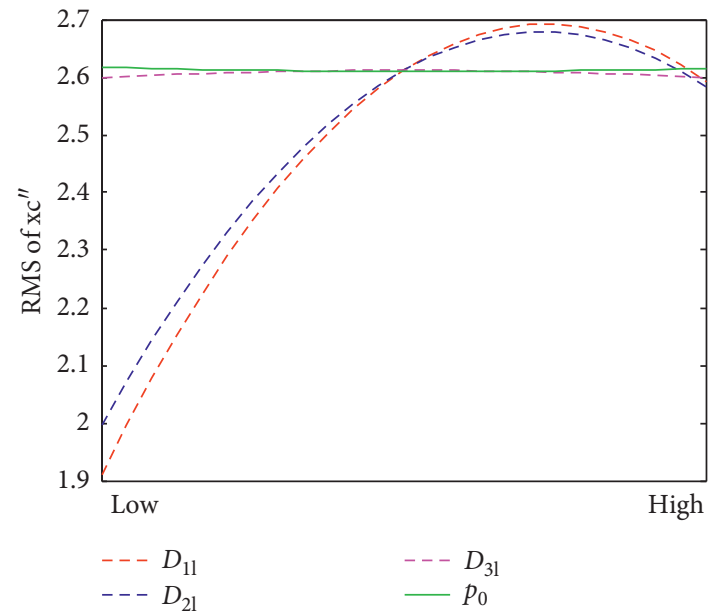

(a)

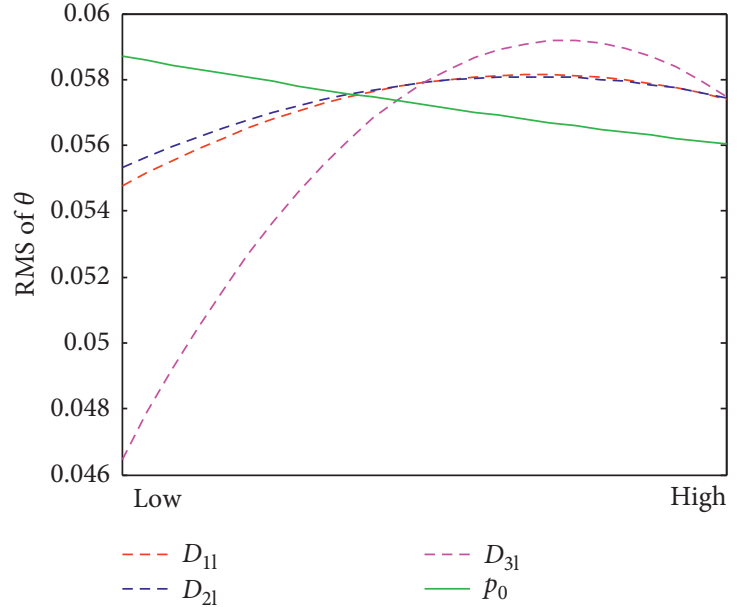

(b)

Figure 7: Main effect graph.

From Figure 8, it can be found that the elastic force and the damping force in the roll mode are much larger than that in the bounce mode. Thus, two conclusions can be drawn: first, the elastic force and damping force negligibly affect the ride comfort in the bounce mode and second, the elastic force and the damping force in roll mode will promptly increase to provide antiroll moment to improve the antiroll performance.

For the result of sensitivity analysis, and the results of elastic and damping characteristics analysis, the main reason can be explained as follows: in the bounce mode, most of the liquid cross flows between the hydraulic cylinder chambers, and only a small part flows into the accumulators. As a result, the damping effect of the throttle valves connecting to the hydraulic cylinder chambers is fully played. By contrast, the contribution of the throttle valves below the accumulators is small, and the gas pressure change in the accumulator is very limited. In the roll mode, the situation is just the opposite; most of the liquid flows into accumulators, which makes full use of the damping effect of the throttle valves under the accumulator and causes the gas pressure in the accumulator to increase rapidly.

Thus far, the above analysis provides a scientific basis for developing a HIS-based semiactive control method to improve the ride comfort and antiroll performance. The principle of the proposed novel HIS-based semiactive control system can be seen as Figure 9: to improve the ride comfort by adjusting the diameters of throttle valves connecting to the hydraulic cylinders and to improve the antiroll performance by adjusting the diameters of throttle valves connecting to the accumulators.

\section{HIS-Based Semiactive Control and Optimization}

4.1. Semiactive Control for Improving Ride Comfort and Antiroll Performance. As previously stated, the sky-hook control method is adopted in this study. Therefore, the
HIS-based semiactive control strategy can be summarized as follows:

To improve ride comfort:

$$
\begin{aligned}
& \text { if } \dot{x}_{s j}\left(\dot{x}_{s j}-\dot{x}_{u j}\right) \geq 0, D_{1 j}=D_{\min 1}, D_{2 j}=D_{\min 2} \\
& \text { if } \dot{x}_{s j}\left(\dot{x}_{s j}-\dot{x}_{u j}\right)<0, D_{1 j}=D_{\max 1}, D_{2 j}=D_{\max 2}
\end{aligned}
$$

To improve antiroll performance:

$$
\begin{aligned}
& \text { if } a_{y} \geq a_{y 0}, D_{3 j}=D_{\min 3} \\
& \text { if } a_{y}<a_{y 0}, D_{3 j}=D_{\max 3}
\end{aligned}
$$

where $a_{y 0}$ is the switched threshold of lateral acceleration and $D_{\min }$ and $D_{\max }$ are the minimize and maximize values of throttle valves, respectively.

4.2. Dual-Frequency-Range Switching Strategy and Optimization for HIS-Based Semiactive with Constraints. The research by Savaresi and Spelta [11] showed that the control effect of the sky-hook max-min damping switched strategy is remarkable when the excitation frequency nears the lower resonant frequency of sprung mass; otherwise, it performs similarly to or sometimes even worse than a passive suspension. Accordingly, a dual-frequency-range switching strategy is proposed in this study for the HIS-based semiactive control system. Specifically, when excitation frequency is lower than a threshold frequency, the HIS-based semiactive suspension adopts a group of maximum and minimum damping coefficients corresponding to lowfrequency control strategy, and when the excitation frequency increases to a threshold, then the HIS-based semiactive suspension will switch to another group of maximum and minimum damping coefficients corresponding to highfrequency control strategy, where the appropriate values of the two groups of maximum and minimum damping coefficients are implemented by parameters optimization based on the sensitivity analysis.

For the optimization of ride comfort, the diameters of throttle valves connecting to hydraulic cylinders are selected 


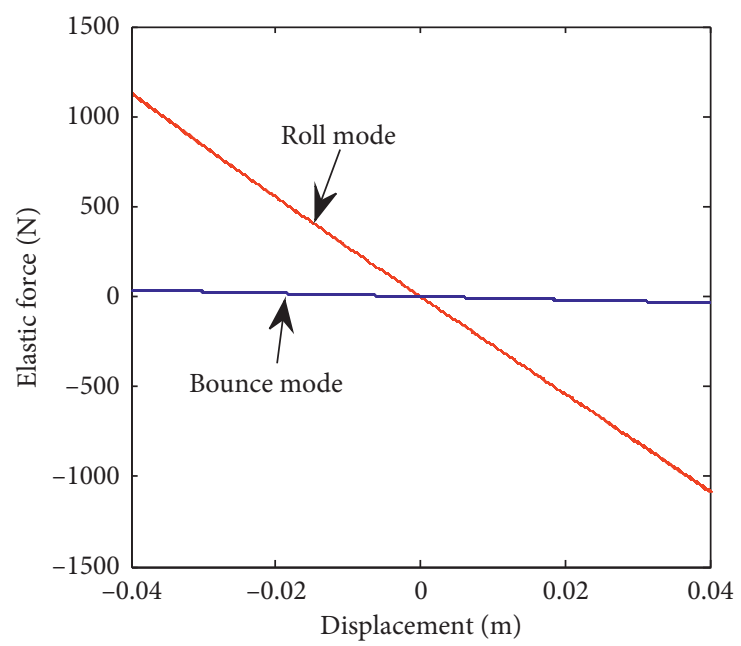

(a)

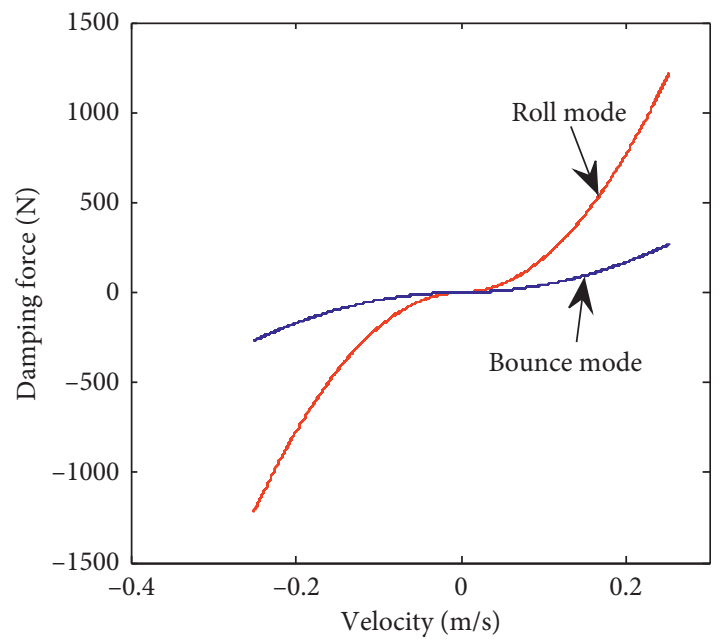

(b)

FIGURE 8: Elastic force and damping force in the two modes.

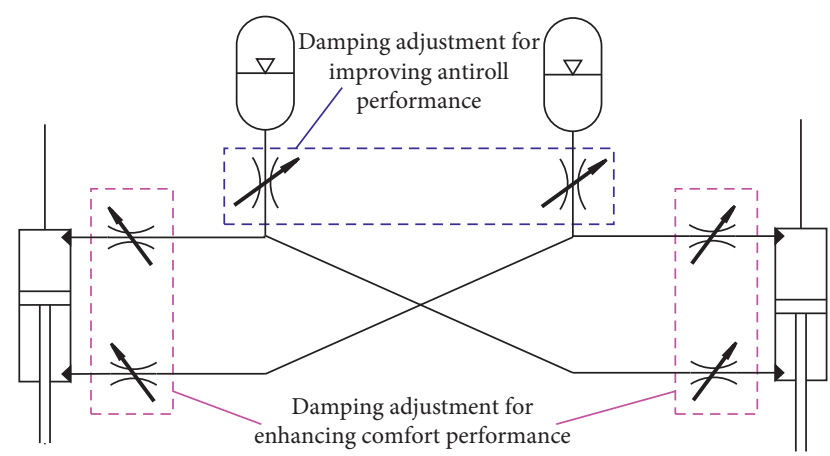

FIgURE 9: Novel semiactive control system based on HIS system.

as optimization variables, the algebraic sum of weighted RMS value of body vertical acceleration and weighted max absolute value of body vertical acceleration is taken as the optimization objective function, and suspension deflection and tire dynamic load are used as constraints. On the basis of ride comfort optimization, we select the diameters of throttle valves connecting to accumulators as optimization variables and treat the RMS value of roll angle as the optimization objective function to improve the antiroll performance for the HIS-based semiactive control system. Finally, the optimization scheme is listed in Table 3.

Using the data listed in Table 4, in accordance with the requirements in Table 3, the optimizations are performed in the joint environment of Isight and MATLAB. The optimized results for HIS-based semiactive control using sky-hook max-min damping switched method are listed in Table 5.

4.3. Frequency-Range Selector for the HIS-Based Semiactive Dual-Frequency Switching Control System. In Section 4.2, the parameter optimization for the low-frequency and highfrequency strategies was completed. Then, the critical issue of the proposed dual-frequency switching control becomes to how to identify the excitation frequency range.

Considering that online identification of road excitation frequency has been a difficult research problem, especially for random road excitation with multiple frequency components, Savaresi and Spelta [11] suggested the optimal-control problem cannot be solved in a realtime implementation but can be solved numerically offline by making the simplifying assumption that the road profile is a pure sinusoid. We also assume the road profile is a pure sinusoid but modifies a frequency-range selector to identify the frequency range of the sinusoidal road excitation online.

For a step excitation damping system, the transient response will disappear after a period of time, and the vibration frequency of the steady-state response will be the same as that of the excitation. Therefore, the road excitation frequency may be determined by the body vertical acceleration steady-state response. Based on this principle, Savaresi and Spelta [11] proposed an approach for frequency-selector; he constructed a symbolic decision function as shown in equation (28), and the relationship between the excitation frequency $\omega$ and the threshold frequency $\omega_{0}$ used for switching the ride comfort control strategy is judged by the sign of $f(t)$ :

$$
f(t)=\ddot{x}(t)^{2}-\omega_{0}^{2} \dot{x}(t)^{2},
$$

where $x(t)$ and $\dot{x}(t)$ are the sprung mass vertical displacement and vertical velocity, whose frequency is regarded as the road excitation frequency and assumed as $\omega . \omega_{0}$ is the threshold frequency; when $f(t)>0$, then $\omega>\omega_{0}$; otherwise, $\omega<\omega_{0}$.

The approach developed by Savaresi is novel and meaningful. Based on the work of Savaresi, a further analysis was carried out: for the sinusoidal road input, assuming sprung mass displacement response as $x(t)=A \sin (\omega t)$, then $\dot{x}(t)=A \omega \cos (\omega t)$ and $\ddot{x}(t)=-A \omega^{2} \sin (\omega t)$, thus $f(t)=A^{2} \omega^{2}\left(\omega^{2} \sin ^{2}(\omega t)-\omega_{0}^{2} \cos ^{2}(\omega t)\right)$. Apparently, there is a phase difference of 90 degrees between $\sin (\omega t)$ and 
TABle 3: Parameter optimization for HIS-based semiactive control suspension system.

\begin{tabular}{|c|c|c|c|c|c|}
\hline Parameter & Symbol & Remark & Scale & $\begin{array}{l}\text { Optimization objective } \\
\text { function }\end{array}$ & Constraints \\
\hline $\begin{array}{l}\text { The diameter of throttle valve connecting to } \\
\text { the rodless chamber in front axle }\end{array}$ & $\begin{array}{l}D_{1 \mathrm{fl}} \\
D_{1 \mathrm{fr}}\end{array}$ & $D_{1 \mathrm{fl}}=D_{1 \mathrm{fr}}$ & {$[2,8](\mathrm{mm})$} & Bounce mode: & \\
\hline $\begin{array}{l}\text { The diameter of throttle valve connecting to } \\
\text { the rodless chamber in rear axle }\end{array}$ & $\begin{array}{l}D_{1 \mathrm{rr}} \\
D_{2 \mathrm{rr}}\end{array}$ & $D_{1 \mathrm{rl}}=D_{1 \mathrm{rr}}$ & {$[2,8](\mathrm{mm})$} & $\min \left(f_{1} \sqrt{(1 / N) \sum_{i=1}^{N} \ddot{x}_{c}(i)^{2}}\right)$ & $\left\{\begin{array}{l}\left|x_{s j 0}-x_{\mathrm{u} j 0}\right| \leq 0.08 \\
\left|x_{\mathrm{u} j 0}-x_{\mathrm{t} j 0}\right| k_{\mathrm{t} j 0} \leq G_{\mathrm{s} j 0}\end{array}\right.$ \\
\hline $\begin{array}{l}\text { The diameter of throttle valve connecting to } \\
\text { the rod chamber in front axle }\end{array}$ & $\begin{array}{l}D_{2 f l} \\
D_{2 \mathrm{fr}}\end{array}$ & $D_{2 \mathrm{fl}}=D_{2 \mathrm{fr}}$ & {$[2,8](\mathrm{mm})$} & $\begin{array}{l}\text { where } f_{1} \text { and } f_{2} \text { are } \\
\text { weighted coefficients }\end{array}$ & $\begin{array}{c}\text { where } G_{s j 0} \text { is the static } \\
\text { load of every wheel }\end{array}$ \\
\hline $\begin{array}{l}\text { The diameter of throttle valve connecting to } \\
\text { the rod chamber in rear axle }\end{array}$ & $\begin{array}{l}D_{2 \mathrm{rl}} \\
D_{2 \mathrm{rr}}\end{array}$ & $D_{2 \mathrm{rl}}=D_{2 \mathrm{rr}}$ & {$[2,8](\mathrm{mm})$} & and $N$ is the sampling point & \\
\hline $\begin{array}{l}\text { The diameter of throttle valve connecting to } \\
\text { the accumulator in front axle }\end{array}$ & $\begin{array}{l}D_{3 \mathrm{fl}} \\
D_{3 \mathrm{fr}}\end{array}$ & $D_{3 \mathrm{fl}}=D_{3 \mathrm{fr}}$ & {$[2,8](\mathrm{mm})$} & Roll mode: & \\
\hline $\begin{array}{l}\text { The diameter of throttle valve connecting to } \\
\text { the accumulator in rear axle }\end{array}$ & $\begin{array}{l}D_{3 \mathrm{rl}} \\
D_{3 \mathrm{rr}}\end{array}$ & $D_{3 \mathrm{rl}}=D_{3 \mathrm{rr}}$ & {$[2,8](\mathrm{mm})$} & $\min \left(\sqrt{(1 / N) \sum_{i=1}^{n} \theta(i)^{2}}\right)$ & $P_{\max } \leq 10 \mathrm{Mpa}$ \\
\hline Precharge pressure in accumulator & $p_{0}$ & & {$[5 \mathrm{e} 5,25 \mathrm{e} 5](\mathrm{pa})$} & & \\
\hline
\end{tabular}

TABLE 4: Parameter values for the HIS-based semiactive control suspension.

\begin{tabular}{lcc}
\hline Parameter & Symbol & Value \\
\hline Vehicle mass $(\mathrm{kg})$ & $m$ & 1390 \\
Sprung mass $(\mathrm{kg})$ & $m_{\mathrm{s}}$ & 1210 \\
Unsprung mass $(\mathrm{kg})$ & $m_{\mathrm{uj} 0}$ & 45 \\
Spring stiffness $(\mathrm{N} / \mathrm{m})$ & $k_{j}$ & 18000 \\
Tire stiffness $(\mathrm{N} / \mathrm{m})$ & $k_{\mathrm{t} j}$ & 200000 \\
Roll moment of inertia $\left(\mathrm{kg} \cdot \mathrm{m}^{2}\right)$ & $I_{\theta}$ & 390 \\
$\begin{array}{l}\text { Pitch moment of inertia }\left(\mathrm{kg} \cdot \mathrm{m}^{2}\right) \\
\text { Yaw moment of inertia }\left(\mathrm{kg} \cdot \mathrm{m}^{2}\right)\end{array}$ & $I_{\varphi}$ & 1920 \\
$\begin{array}{l}\text { Height of the sprung mass center } \\
\text { of gravity from the roll center }(\mathrm{m})\end{array}$ & $I_{z}$ & 2000 \\
$\begin{array}{l}\text { Track width (m) } \\
\text { Distance from vehicle center of gravity }\end{array}$ & $h$ & 0.3 \\
to the front axle $(\mathrm{m})$ & $b_{s}$ & 1.48 \\
$\begin{array}{l}\text { Distance from vehicle center of gravity } \\
\text { to the rear axle }(\mathrm{m})\end{array}$ & $b$ & 1.13 \\
$\begin{array}{l}\text { Discharge coefficient } \\
\text { Liquid action areas of the rodless } \\
\text { chamber }\left(\mathrm{m}^{2}\right)\end{array}$ & $c_{\mathrm{d}}$ & 0.6 \\
$\begin{array}{l}\text { Liquid action areas of the rod } \\
\left.\text { chamber (m }{ }^{2}\right)\end{array}$ & $A_{1}$ & $3.8 \times 10^{-4}$ \\
\hline
\end{tabular}

$\cos (\omega t)$, and thus, the sign of $f(t)$ cannot always represent the relationship between the excitation frequency $\omega$ and the threshold frequency $\omega_{0}$.

We proposed an improved method, and the function is defined as $F(t)$ in the following equation:

$$
F(t)=|\ddot{x}(t)|-\omega_{0}^{2}|x(t)| .
$$

According to the above assumptions, $F(t)=$ $A \omega^{2}|\sin (\omega t)|-A \omega_{0}^{2}|\sin (\omega t)|$. Because $|\sin (\omega t)| \geq 0, F(t)$ will have the same sign with $\omega^{2}-\omega_{0}^{2}$; namely, if $F(t)>0$, then $\omega>\omega_{0}$, and otherwise, $\omega<\omega_{0}$.

Taking the vibration response of common passive suspension under road excitations of $0.04 \sin (2 \pi t)$ and $0.04 \sin (6 \pi t)$ as examples, setting the threshold frequency as $\omega_{0}=3.5 \pi$, which will be specially explained in Section 5.1, the accuracy of the $F(t)$ frequency-range selector and the $f(t)$ frequency-selector is analyzed below.
Figure $10(a)$ shows that the $f(t)$ frequency-range selector is accurate during most of each cycle, but it can only approximate the relationship between $\omega$ and $\omega_{0}$, which means that the semiactive control in some period cannot switch in accordance with designed requirement.

As shown in Figure 10, it can be determined that, compared to the $f(t)$ frequency-range selector, the $F(t)$ frequency-range selector can be more accurate, which provides a more reliable basis for dual-frequency switching control.

However, the above comparisons are based on the offline data of the passive suspension system. It should be noted that, for the semiactive suspension using the sky-hook algorithm, the damping coefficient will be frequently switched between the maximum and minimum values, and there will be a transient response period after every switching, which may lead to incorrect judgment for the $F(t)$ frequency-range selector.

The online judgment results of the $F(t)$ frequency-range selector for the proposed semiactive control system in the excitation frequencies of $2 \pi$ and $6 \pi$ are shown in Figures 11 and 12 . Owing to interference by the transient response, the judgment results in errors in the two different excitation frequencies, causing the vibration response appearing to abruptly change.

Considering that, because of the existence of the damping, the transient response caused by damping coefficient switching will be soon attenuated, it can be known that the proportion of the vibration energy of the transient response caused by damping coefficient switching is relatively small. Thereafter, we further improve the $F(t)$ frequency-selector by using the energy moving average (EMA) method to filter out the impact of transient response. The specific process of EMA method is as follows:

(1) Defining $k$ as a fixed number, the average energy of $k$ points according to equations (30) and (31) is calculated.

Note that $n_{1}$ is the number of test points; when it is less than $k$, the low-frequency control strategy is adopted by default: 
TABLe 5: Optimized results.

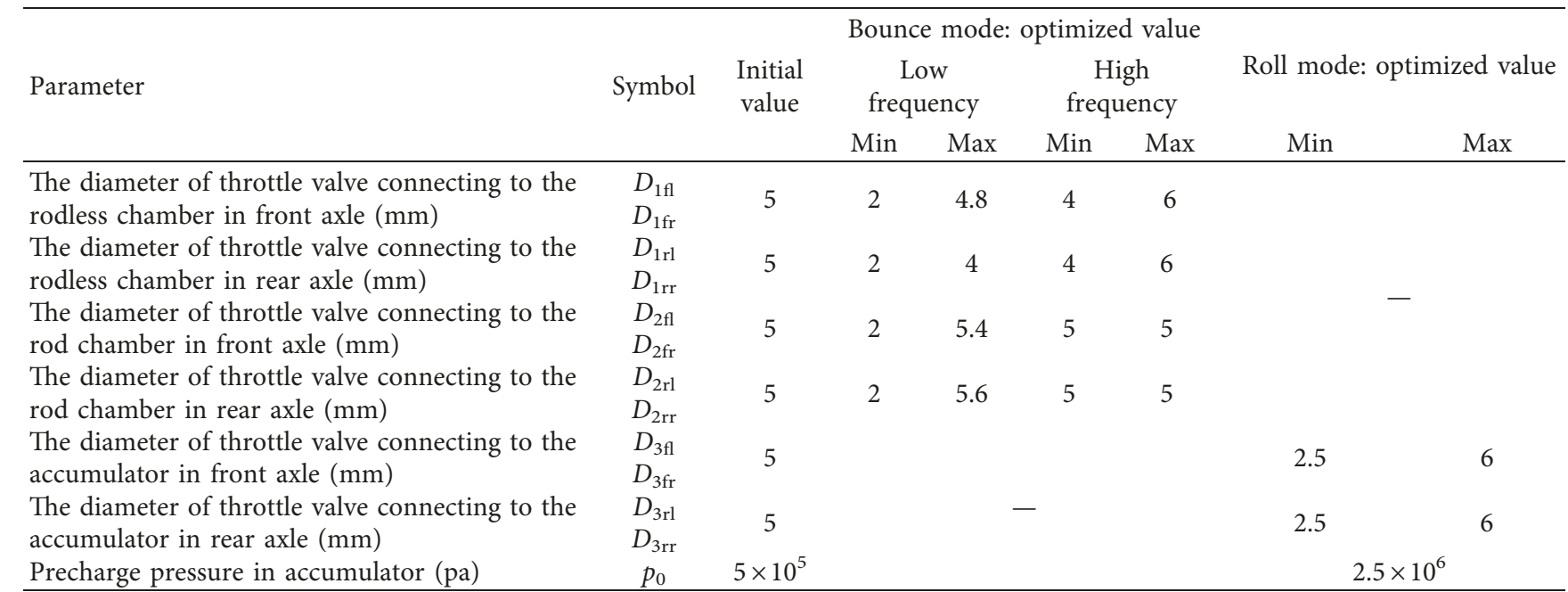
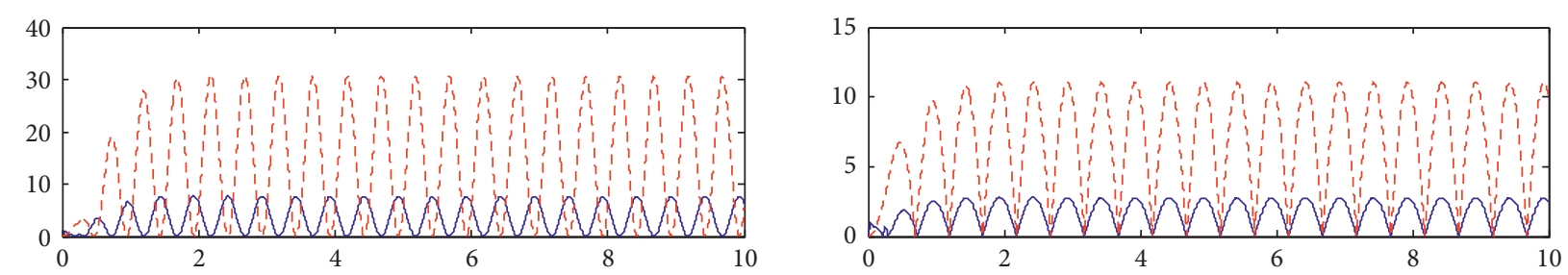

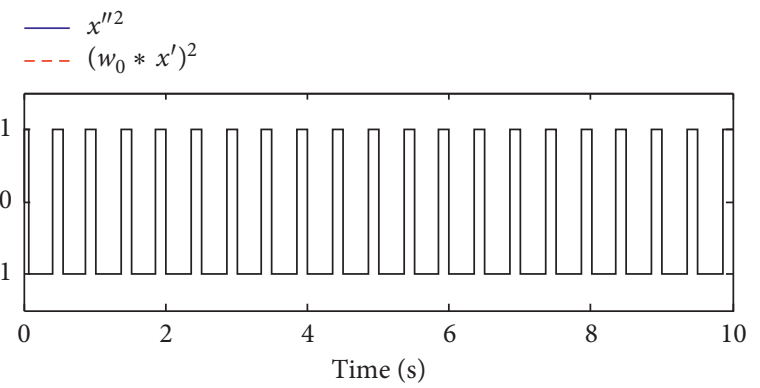

(a)

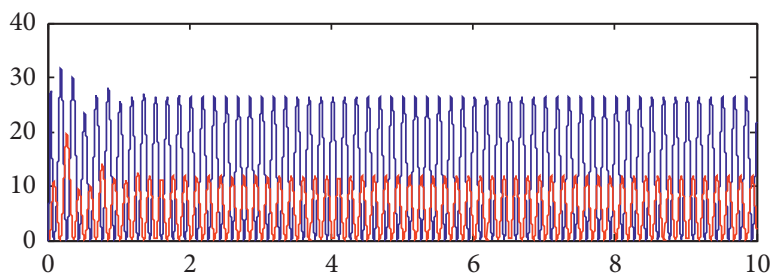

$x^{\prime \prime 2}$
$-w_{0}^{2} * x^{\prime 2}$

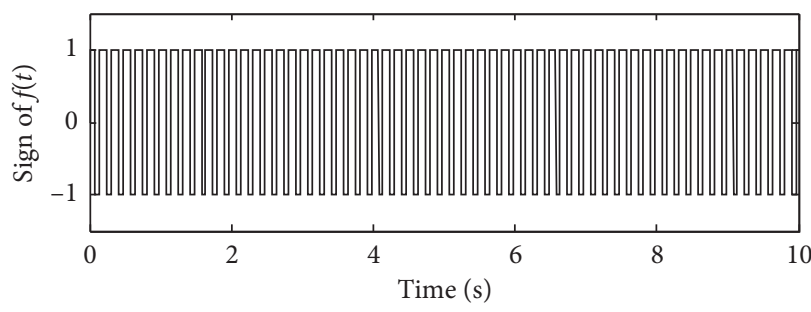

(c)

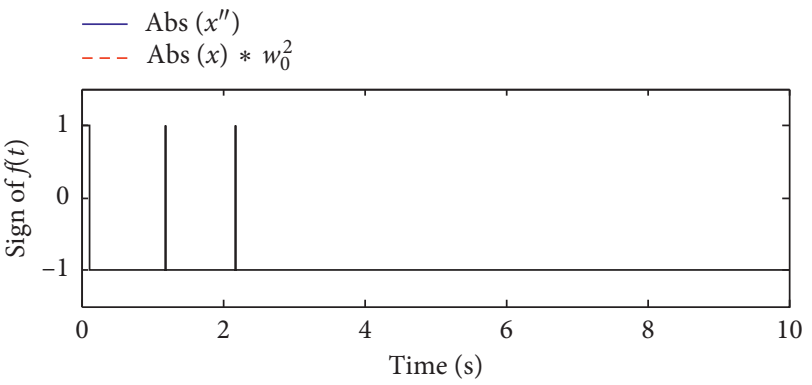

(b)

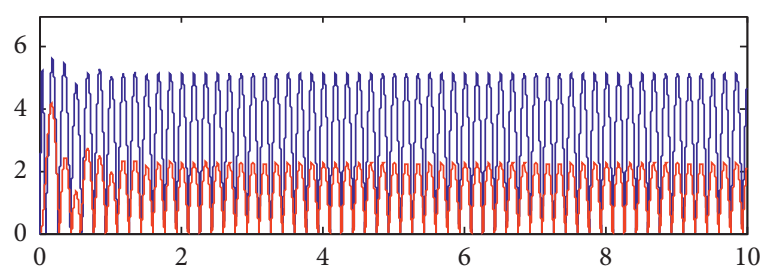

$-\operatorname{Abs}\left(x^{\prime \prime}\right)$

$-\operatorname{Abs}(x) * w_{0}^{2}$

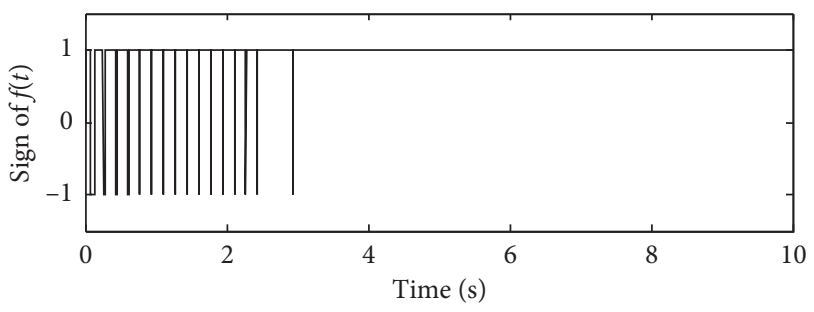

(d)

FiguRE 10: Results of frequency-range selector for passive suspension. Road excitation frequency of (a) $2 \pi$, (b) $2 \pi$, (c) $6 \pi$, and (d) $6 \pi$. 

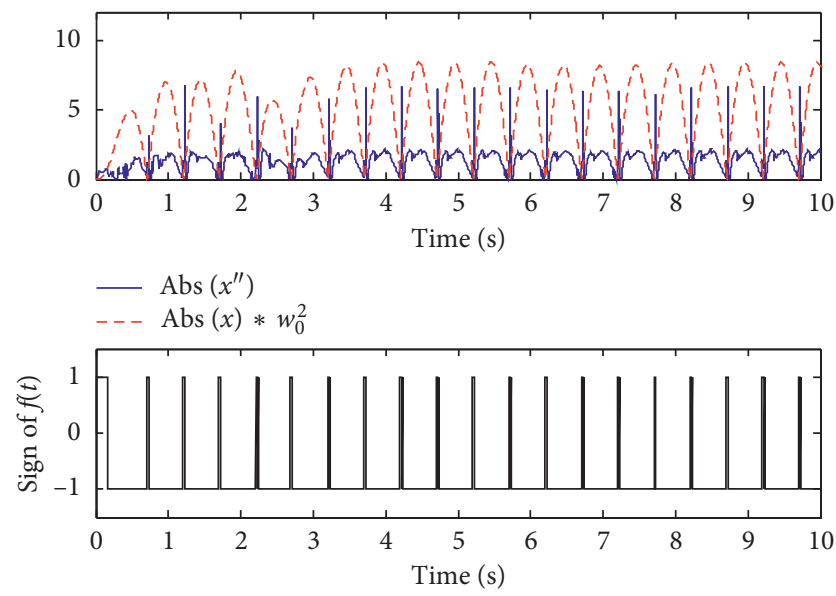

Figure 11: Results of $F(t)$ frequency-range selector for the semiactive suspension when excitation frequency is $2 \pi$.
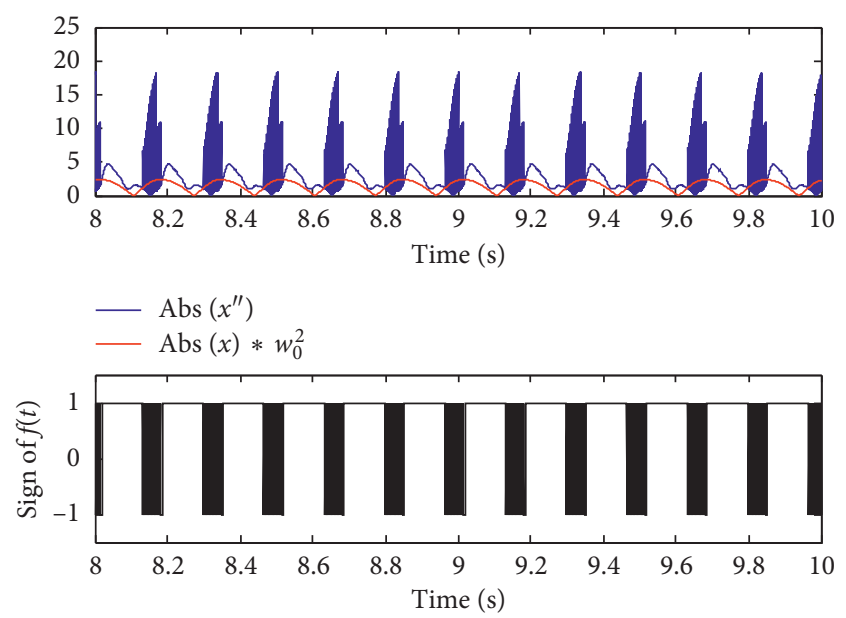

FIGURE 12: Results of $F(t)$ frequency-range selector for the semiactive suspension when excitation frequency is $6 \pi$.

$$
\begin{aligned}
& H\left(n_{1}-k\right)=\frac{1}{k} \sum_{n_{1}-k}^{n_{1}-1} \ddot{x}_{c}(i)^{2}, \\
& P\left(n_{1}-k\right)=\frac{1}{k} \sum_{n_{1}-k}^{n_{1}-1}\left(\omega_{0}^{2} x_{c}(i)\right)^{2},
\end{aligned}
$$

$$
\begin{aligned}
F\left(n_{1}-k\right)= & H\left(n_{1}-k\right)-P\left(n_{1}-k\right)=\frac{1}{k} \sum_{n_{1}-k}^{n_{1}-1} \ddot{x}_{c}(i)^{2} \\
& -\frac{1}{k} \sum_{n_{1}-k}^{n_{1}-1}\left(\omega_{0}^{2} x_{c}(i)\right)^{2} .
\end{aligned}
$$

(2) Comparing $H\left(n_{1}-k\right)$ with $P\left(n_{1}-k\right)$, if $H\left(n_{1}-k\right)<P\left(n_{1}-k\right)$, namely, $F\left(n_{1}-k\right)<0$, it can be deduced that $\omega<\omega_{0}$, and the semiactive control adopts the low-frequency strategy. Otherwise, the semiactive control switches to the high-frequency strategy.

The judgment results of EMA frequency-selector for the HIS-based semiactive control system, under the sinusoidal road excitations with frequency of $2 \pi$ and $6 \pi \mathrm{rad} / \mathrm{s}$, are shown in Figure 13.

Figure 13 shows that, when the excitation frequencies are, respectively, $2 \pi$ and $6 \pi$ and the threshold frequency is $3.5 \pi$, the EMA frequency-range selector accurately judges the relationship between the excitation frequency and the threshold frequency, which indicates that the EMA frequency-selector proposed in this paper is accurate and feasible.

Thus far, the principle of the proposed HIS-based semiactive dual-frequency-range switching control system can be described, as shown in Figure 14 .

\section{Simulations and Analysis}

5.1. Response Analysis in the Frequency Domain. The frequency response of "Body vertical acceleration-Road excitation" is usually used to depict the improvement of vehicle ride comfort, but the notion of frequency response is not well defined for a strongly nonlinear semiactive control caused by damping switch. Thus, the amplitude-frequency characteristic is obtained by counting the ratio of output energy to input energy in different excitation frequencies, as shown in the following equation:

$$
H\left(j \omega_{i}\right)=\sqrt{\frac{\left(1 / N_{1}\right) \sum_{q=1}^{N_{1}}\left[\ddot{x}_{\mathrm{c}}(q)-\ddot{\ddot{x}}_{\mathrm{c}}\right]^{2}}{\left(1 / N_{1}\right) \sum_{q=1}^{N_{1}}\left[x_{\mathrm{t}}(q)-\overline{x_{\mathrm{t}}}\right]^{2}}},
$$

where $j$ is a complex symbol, $x_{t}(t)$ is the road excitation, $\ddot{x}_{\mathrm{c}}$ is the average body vertical acceleration, $\overline{x_{t}}$ is the mean value of road excitation, $N_{1}$ is the number of sampling points, and $\omega_{i}$ represents the excitation frequency.

The amplitude-frequency characteristics of "Body vertical acceleration-Road excitation" for 4 cases listed in Table 6 are obtained in Figure 15.

From Figure 15, compared with passive suspension corresponding to Case 4, it can be found that (1) for Case 2 , the first resonance peak obviously reduces, but the amplitude ratio increases in the frequency-range higher than the first resonance frequency, which indicates that the ride comfort is improved in the first resonance frequency but deteriorates in the second resonance frequency; (2) for Case 3, the first resonance peak obviously increases, and the amplitude ratio reduces in the frequency range between the first and second resonance frequencies; and (3) Case 1 combines the advantages of Case 2 and Case 3, indicating that the proposed control system improves the ride comfort in a wider frequency range.

Incidentally, from Figure 15, the intersection frequency of the amplitude-frequency characteristics curves for low-frequency and the high-frequency strategies is approximately $11 \mathrm{rad} / \mathrm{s}$, which is the reason we select the threshold frequency as $3.5 \pi$. 

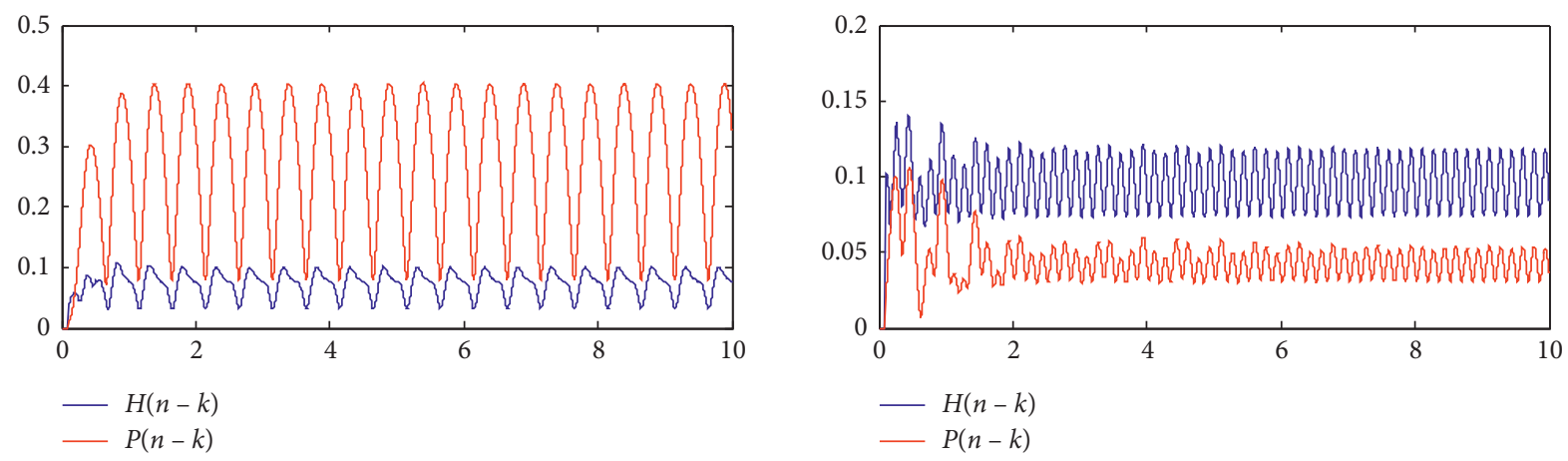

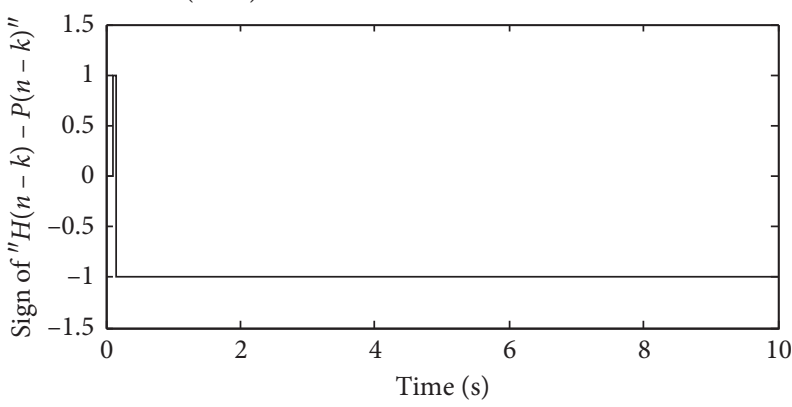

(a)

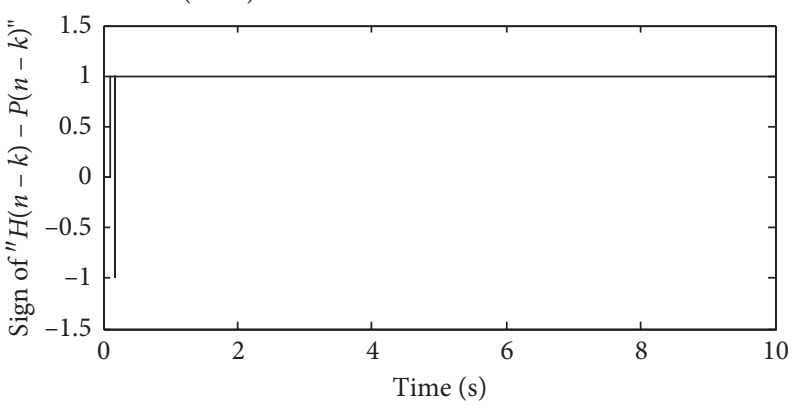

(b)

Figure 13: Judgment results of EMA frequency-range selector. Road excitation frequency of (a) $2 \pi$ and (b) $6 \pi$.

\subsection{Time-Domain Simulations and Analysis}

5.2.1. Straight Forward with Sinusoidal Excitation. To test the effectiveness and superiority of the proposed semiactive control system in improving the ride comfort, the timedomain simulations of passive suspension, common semiactive control suspension, and the proposed HIS-based semiactive dual-frequency switching control suspension are analyzed and compared.

Because the first resonance frequency is the natural frequency of the vehicle body, which significantly affects the ride comfort, semiactive control should ensure that it has a good attenuation effect on body vibration when road excitation frequency nears the first-order resonant frequency. On this basis, in order to make the common semiactive suspension comparable with the proposed HIS-based semiactive suspension, we obtain the maximum and minimum damping coefficients for the common semiactive suspension by linearizing the maximum and minimum damping curves of the proposed semiactive suspension. Figure 16 shows the damping force curves of the proposed semiactive control suspension under a sinusoidal road excitation of $2 \pi \mathrm{rad} / \mathrm{s}$; the solid blue curves show the damping coefficient switches between the max and min values. Fitting the two curves by the least square method, the equivalent maximum and minimum damping coefficients of the common semiactive suspension are obtained as $2810 \mathrm{~N} \cdot \mathrm{s} / \mathrm{m}$ and $292 \mathrm{~N} \cdot \mathrm{s} / \mathrm{m}$, respectively.

Figure 17 shows the body vertical acceleration curves of the proposed and the common semiactive control under a road excitation of $0.04 \sin (2 \pi t)$. The two curves are basically coincident, indicating the two semiactive control systems can achieve nearly the same effect under the low-frequency road excitation condition, which provides a comparable foundation for the higher road excitation frequency comparison.

Figure 18 shows that, under a road excitation of $0.04 \sin (6 \pi t)$, the proposed semiactive control system switches from low-frequency strategy to high-frequency strategy according to the EMA frequency-selector, and the amplitude of the body vertical acceleration is well restrained. As a result, the ride comfort is obviously improved. However, even though most of time, the common semiactive control system can achieve the same control effect as the proposed semiactive control system, there are obvious mutations, causing deterioration of the ride comfort, which is consistent with the conclusions of Savaresi and Spelta [11].

5.2.2. Simulations for Fishhook Test and Step Input Steering. The fishhook test and step input steering simulations for validating the antiroll performance are carried out at a speed of $60 \mathrm{~km} / \mathrm{h}$. Antiroll performance comparisons of passive suspension, common semiactive control suspension, and the proposed semiactive control suspension are shown in Figure 19.

As shown in Figure 19, the common semiactive suspension significantly improves the antiroll performance during the transient steering process, but it cannot improve the antiroll performance during the steady steering process. By contrast, the proposed HIS-based semiactive dualfrequency switching control suspension can improve antiroll performance in both transient and steady-state steering processes.

Figure 19(d) depicts the "Body roll angle-Body roll rate" phase-plane, the common semiactive control, whose roll stability domain is superior to passive suspension. By 


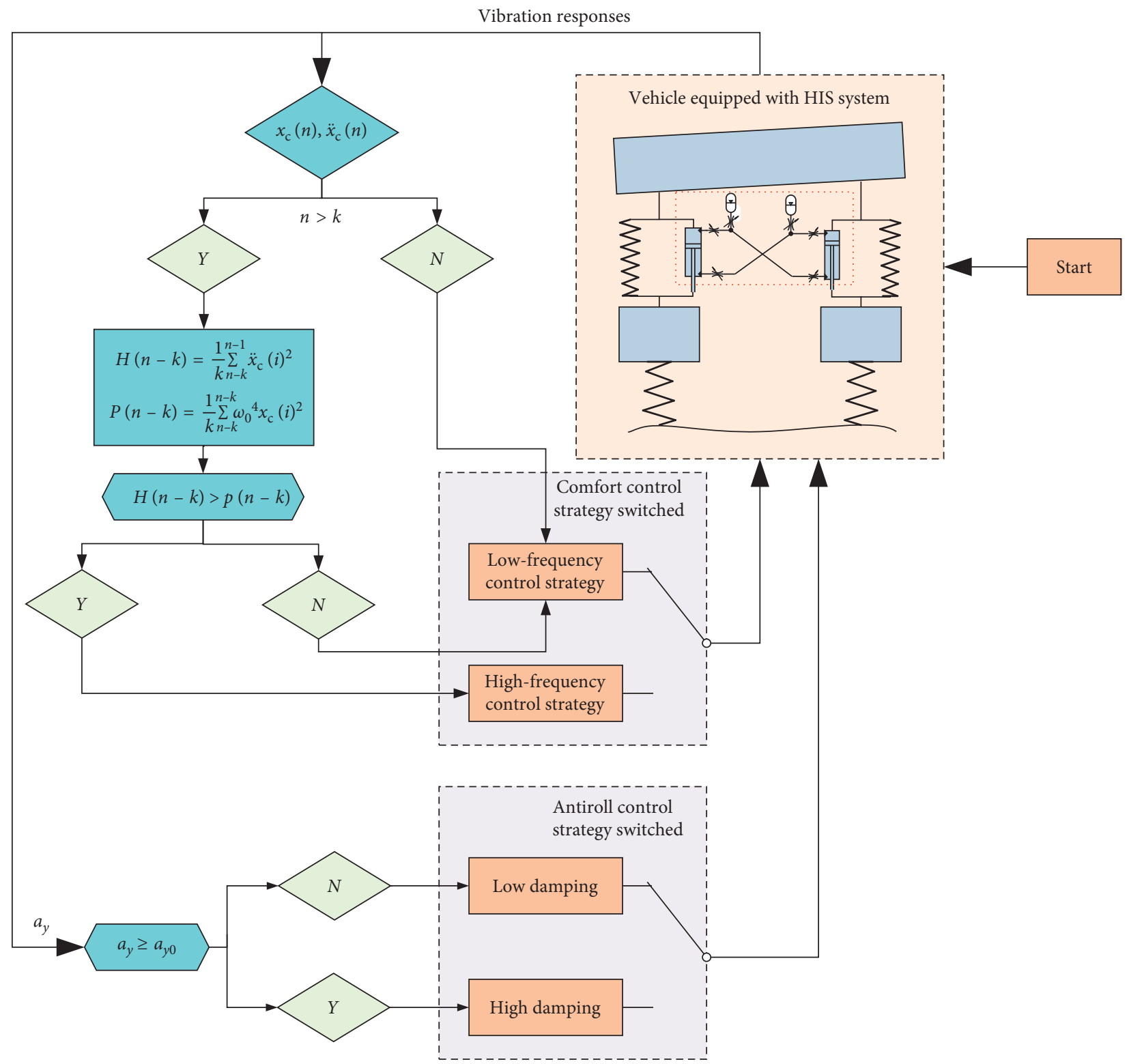

FIGURE 14: Proposed HIS-based semiactive dual-frequency-range switching control system schedule.
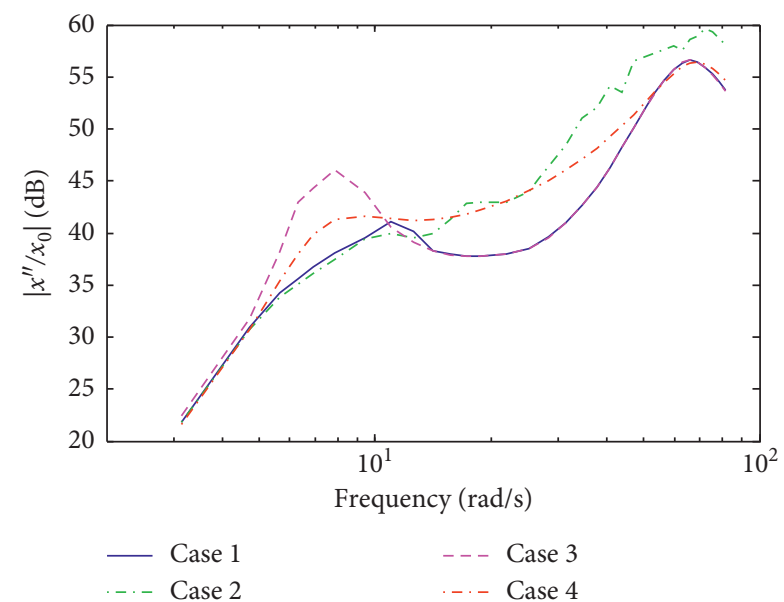

FIGURE 15: Amplitude-frequency characteristics of "Body vertical acceleration-Road excitation."
TABLE 6: Four cases of suspensions for frequency response analysis. Case 1 The proposed HIS-based semiactive dual-frequencyrange switching control strategy

Case 2 The HIS-based semiactive low-frequency control strategy

Case 3 The HIS-based semiactive high-frequency control

Case 4 strategy

Passive suspension

contrast, the roll stability domain of the proposed semiactive control suspension has been further improved.

\section{Conclusions}

In vehicles equipped with an HIS system, sensitivity analysis results show that the sensitivities of ride comfort 


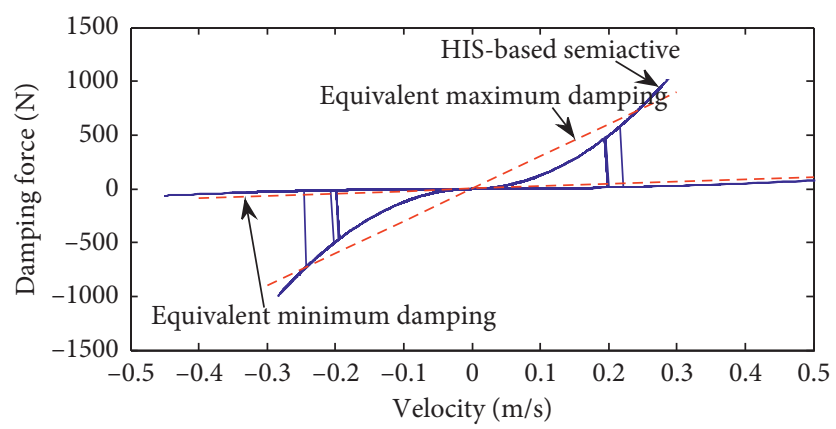

Figure 16: Damping force curves comparison between common semiactive control suspension and the proposed semiactive control suspension.

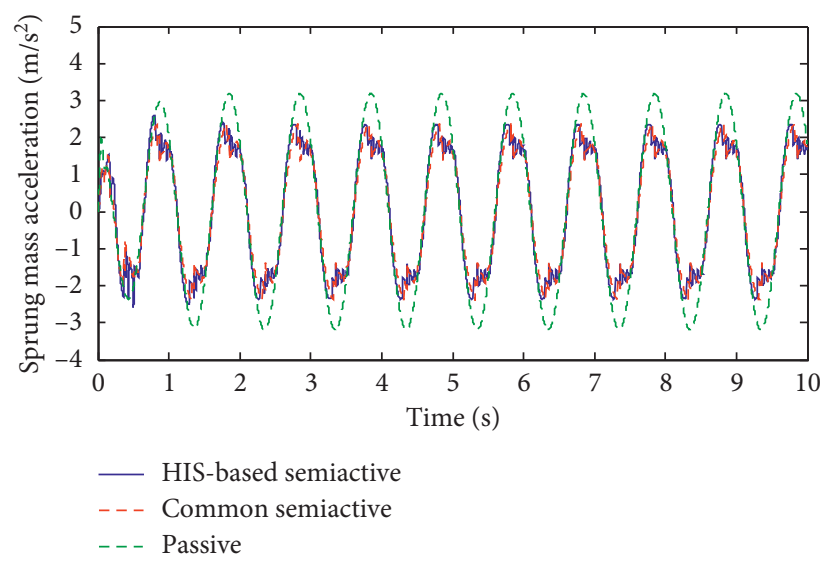

FIGURE 17: Body vertical acceleration comparison between the common semiactive control suspension and the proposed semiactive control suspension.

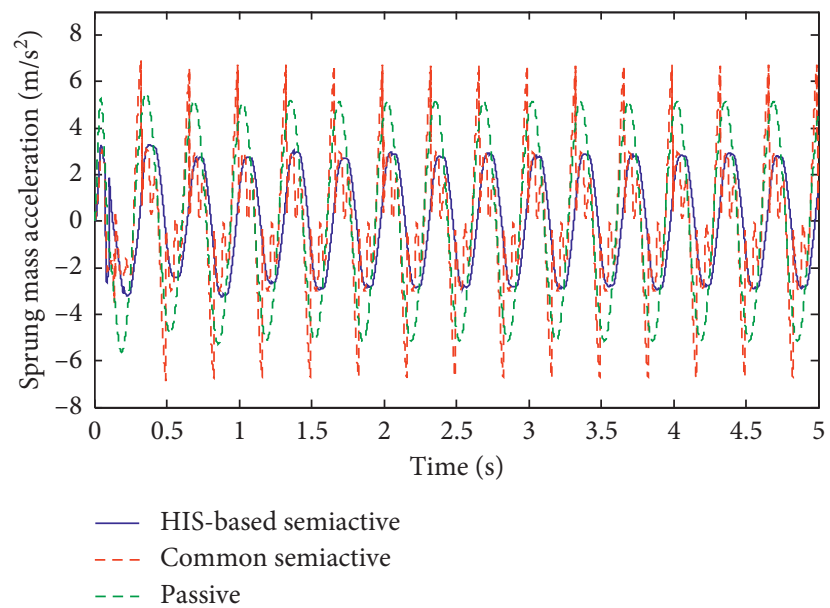

Figure 18: Body vertical acceleration comparisons between the proposed and the common semiactive control suspension under the road excitation period of $6 \pi$.

and antiroll performance to the hydraulic system parameters are complementary. Therefore, a novel HISbased semiactive control method was developed by adjusting the damping aperture of throttle valves connecting to the hydraulic cylinders to improve ride comfort and regulate the flow aperture of throttle valves connecting to the accumulators to enhance antiroll performance.
Thereafter, a dual-frequency-range switching control strategy for improving ride comfort was proposed. The hydraulic system parameters for the low-frequency and the high-frequency sinusoidal road excitations were respectively optimized, and an EMA frequency-range selector was designed to identify the relationship between the excitation frequency and the threshold frequency to switch the ride comfort control strategy. 


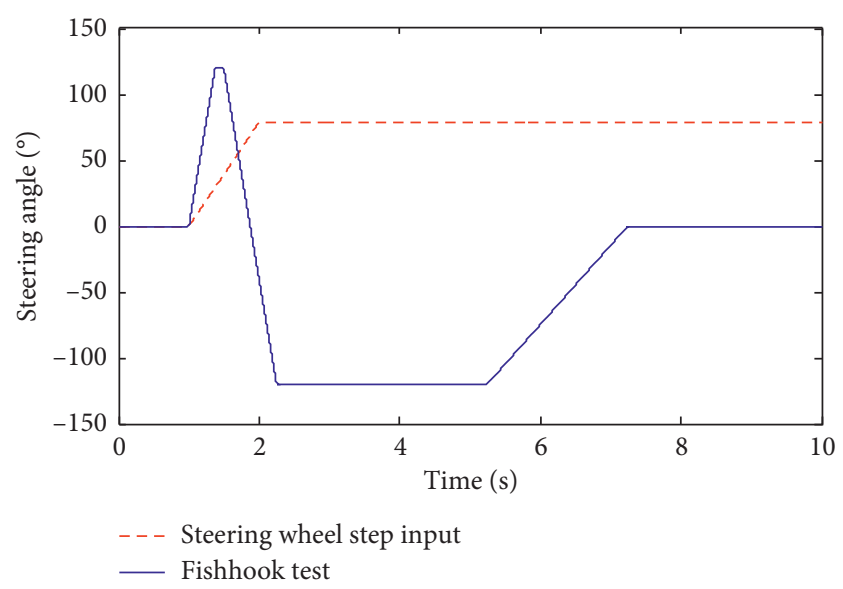

(a)

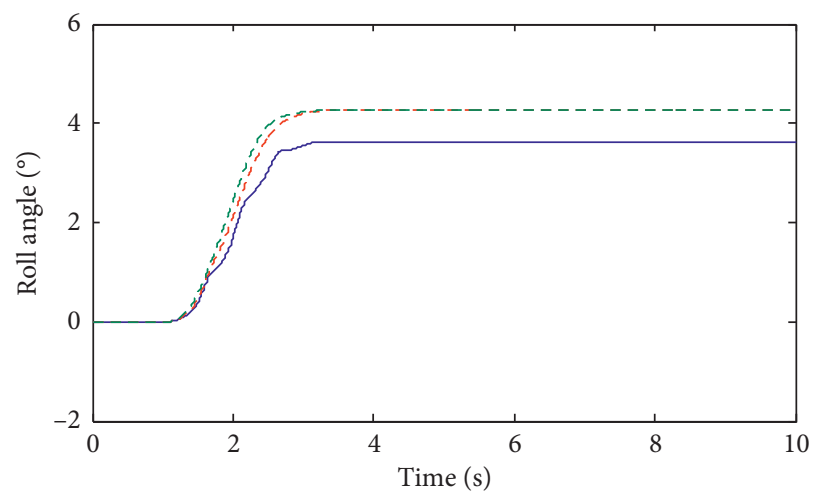

- HIS-based semiactvie
- - Common semiactive
- - Passive

(c)

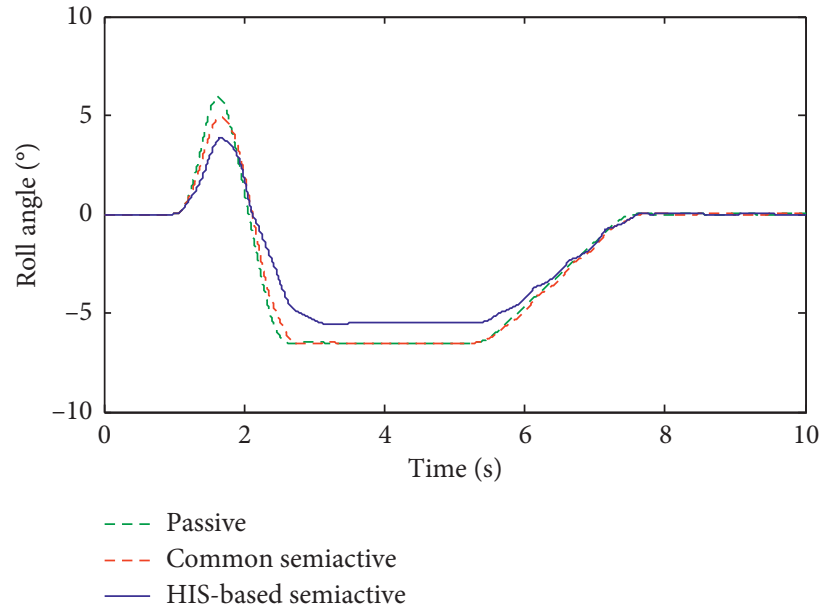

(b)

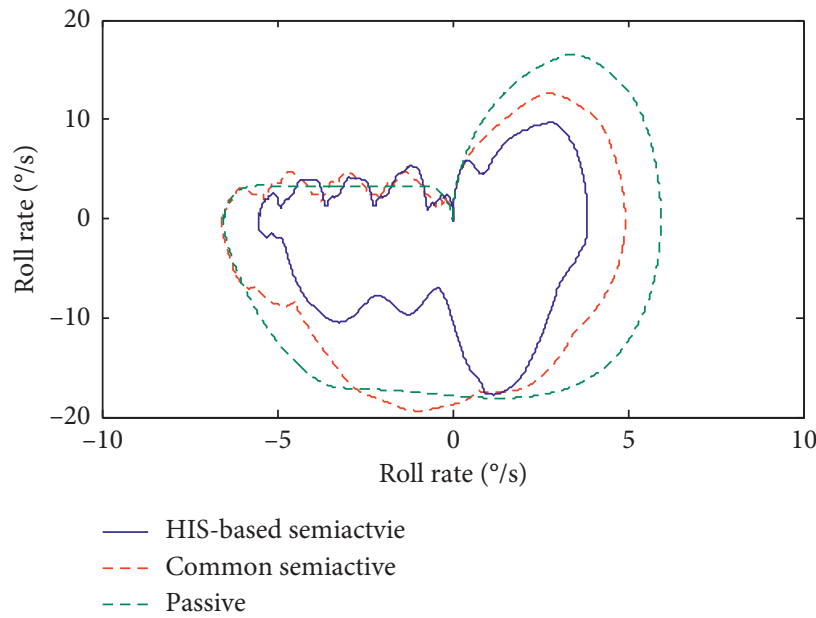

(d)

Figure 19: Comparison of roll angle-roll rate phase-plane for the fishhook test. (a) Steering input. (b) Roll angle for fishhook test. (c) Roll angle for step input steering. (d) "Roll angle-Roll rate" phase-plane for fishhook test.

The analysis in the frequency domain and time domain showed that the proposed HIS-based semiactive dualfrequency-range switching control method can improve vehicle ride comfort in a wider frequency bandwidth and have better antiroll performance than common semiactive suspension.

\section{Appendix}

(1) Sky-hook control strategy:

$$
C= \begin{cases}C_{\max }, & \dot{x}_{\mathrm{s}}\left(\dot{x}_{\mathrm{s}}-\dot{x}_{\mathrm{u}}\right) \geq 0 \\ C_{\min }, & \text { else. }\end{cases}
$$

(2) Ground-hook control strategy:

$$
C= \begin{cases}C_{\max }, & \dot{x}_{\mathrm{u}}\left(\dot{x}_{\mathrm{s}}-\dot{x}_{\mathrm{u}}\right) \leq 0, \\ C_{\min }, & \text { else }\end{cases}
$$

where $C$ is the damping coefficient and $\dot{x}_{\mathrm{s}}$ and $\dot{x}_{\mathrm{u}}$ are the vertical velocity of the sprung mass and unsprung mass, respectively.

\section{Data Availability}

The data used to support the findings of this study are included within the article.

\section{Conflicts of Interest}

The authors declare that there are no conflicts of interest regarding the publication of this article.

\section{Acknowledgments}

This work was supported by the National Natural Science Foundation of China (Grant nos. 51875184, 51762034, and 51765021) and Jiangxi University of Technology Open Fund (Grant no. 16XTKFYB04).

\section{References}

[1] J. Dye, N. BuchMueller, and H. Lankarani, "Semi-active suspension suboptimal control using dynamic programming of a quarter car suspension system," in Proceedings of the 12th International Conference on Multibody Systems, 
Nonlinear Dynamics, and Control, American Society of Mechanical Engineers (ASME), Charlotte, NC, USA, August 2016.

[2] K. El Majdoub, D. Ghani, F. Giri, and F. Chaoui, “Adaptive semi-active suspension of quarter-vehicle with magnetorheological damper," Journal of Dynamic Systems, Measurement, and Control, vol. 137, no. 2, article 021010, 2015.

[3] M. Z. Q. Chen, Y. Yinlong Hu, C. Chanying Li, and G. Guanrong Chen, "Performance benefits of using inerter in semiactive suspensions," IEEE Transactions on Control Systems Technology, vol. 23, no. 4, pp. 1571-1577, 2015.

[4] H. Zhang, E. Wang, N. Zhang, F. Min, R. Subash, and C. Su, "Semi-active sliding mode control of vehicle suspension with magneto-rheological damper," Chinese Journal of Mechanical Engineering, vol. 28, no. 1, pp. 63-75, 2015.

[5] D. Karnopp, M. J. Crosby, and R. A. Harwood, "Vibration control using semi-active force generators," Journal of Engineering for Industry, vol. 96, no. 2, pp. 619-626, 1974.

[6] M. Valásek and M. Novák, "A new concept of semi-active control of truck's suspension," in Proceedings of the International Symposium on Advanced Vehicle Control, pp. 141-151, Aachen, Germany, June 1996.

[7] M. Ahmadian and N. Vahdati, "Transient dynamics of semiactive suspensions with hybrid control," Journal of Intelligent Material Systems and Structures, vol. 17, no. 2, pp. 145-153, 2006.

[8] B. Assadsangabi, M. Eghtesad, F. Daneshmand, and N. Vahdati, "Hybrid sliding mode control of semi-active suspension systems," Smart Materials and Structures, vol. 18, no. 12, article 125027, 2009.

[9] M. M. S. Kaldas, K. Çalişkan, R. Henze, and F. Küçükay, "Development of a semi-active suspension controller using adaptive-fuzzy with kalman filter," SAE International Journal of Materials and Manufacturing, vol. 4, no. 1, pp. 505-515, 2011.

[10] S. A. Kanarachos, "Intelligent semi-active vehicle suspension systems using neural networks," International Journal of Vehicle Systems Modelling and Testing, vol. 7, no. 2, pp. 135-158, 2012.

[11] S. M. Savaresi and C. Spelta, "Mixed sky-hook and ADD: approaching the filtering limits of a semi-active suspension," Journal of Dynamic Systems, Measurement, and Control, vol. 129, no. 4, pp. 382-392, 2007.

[12] S. J. Swift, M. C. Smith, A. R. Glover, C. Papageorgiou, B. Gartner, and N. E. Houghton, "Design and modelling of a fluid inerter," International Journal of Control, vol. 86, no. 11, pp. 2035-2051, 2013.

[13] G. Xu and N. Zhang, "Characteristic analysis of roll and pitch independently controlled hydraulically interconnected suspension," SAE International Journal of Commercial Vehicles, vol. 7, no. 1, pp. 170-176, 2014.

[14] N. Zhang, W. A. Smith, and J. Jeyakumaran, "Hydraulically interconnected vehicle suspension: background and modelling," Vehicle System Dynamics, vol. 48, no. 1, pp. 17-40, 2010.

[15] N. Zhang, L. Wang, and H. Du, "Motion-mode energy method for vehicle dynamics analysis and control," Vehicle System Dynamics, vol. 52, no. 1, pp. 1-25, 2014.

[16] H. Du, N. Zhang, and L. Wang, "Switched control of vehicle suspension based on motion-mode detection," Vehicle System Dynamics, vol. 52, no. 1, pp. 142-165, 2014.

[17] S. Zhu, H. Du, and N. Zhang, "Development and implementation of fuzzy, fuzzy PID and LQR controllers for an rollplane active hydraulically interconnected suspension," in Proceedings of the IEEE International Conference on Fuzzy
Systems (FUZZ-IEEE), pp. 2017-2024, IEEE, Hyderabad, India, July 2014.

[18] W. A. Smith, N. Zhang, and W. Hu, "Hydraulically interconnected vehicle suspension: handling performance," Vehicle System Dynamics, vol. 49, no. 1-2, pp. 87-106, 2011.

[19] W. A. Smith, N. Zhang, and J. Jeyakumaran, "Hydraulically interconnected vehicle suspension: theoretical and experimental ride analysis," Vehicle System Dynamics, vol. 48, no. 1, pp. 41-64, 2010.

[20] Q. Yao, X. Zhang, K. Guo, Y. Yang, and J. Feng, "Study on a novel dual-mode interconnected suspension," International Journal of Vehicle Design, vol. 68, no. 1-3, pp. 81-103, 2015.

[21] R. Wang, Q. Ye, Z. Sun, W. Zhou, Y. Cao, and L. Chen, "A study of the hydraulically interconnected inerter-springdamper suspension system," Mechanics Based Design of Structures and Machines, vol. 45, no. 4, pp. 415-429, 2017.

[22] X. Wu, B. Zhou, G. Wen, L. Long, and Q. Cui, "Intervention criterion and control research for active front steering with consideration of road adhesion," Vehicle System Dynamics, vol. 56, no. 4, pp. 553-578, 2018.

[23] D. Cao, Theoretical analyses of roll-and pitch-coupled hydropneumatic strut suspensions, Ph.D. thesis, Concordia University, Montreal, Canada, 2008. 


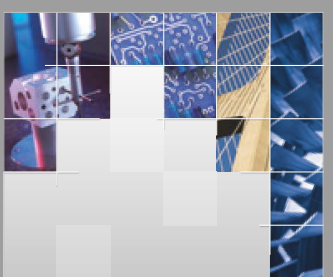

\section{Enfincering}
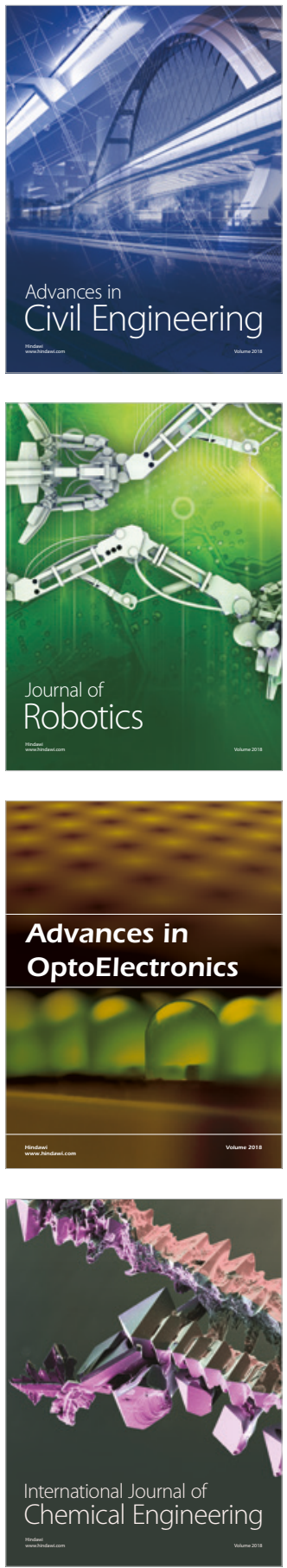

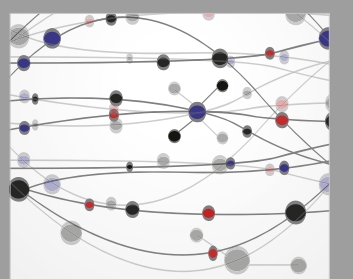

\section{Rotating \\ Machinery}

The Scientific World Journal

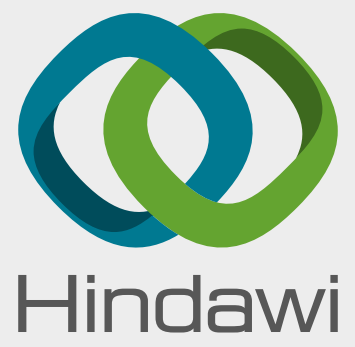

Submit your manuscripts at

www.hindawi.com
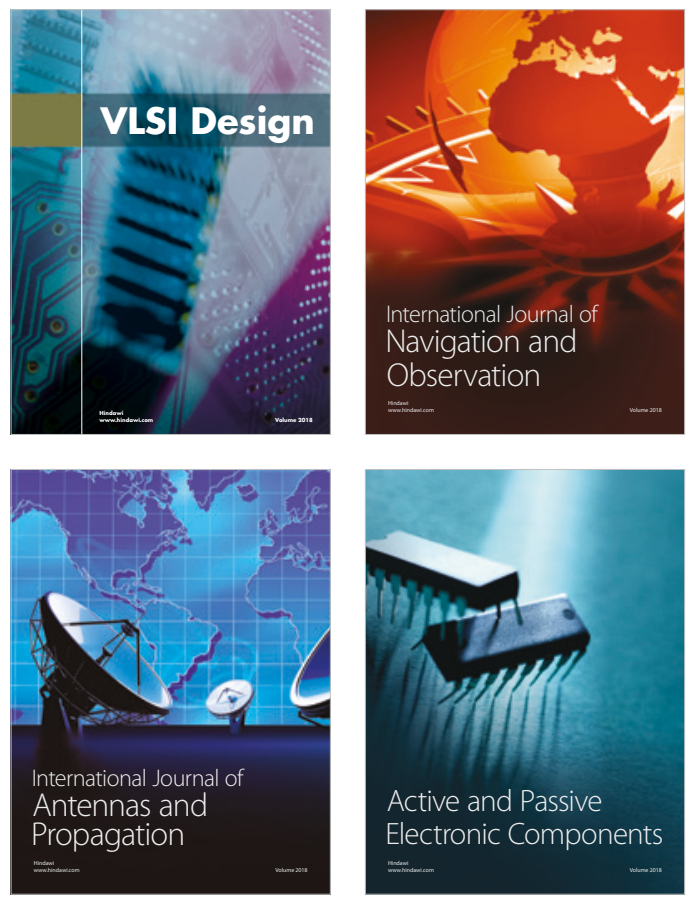
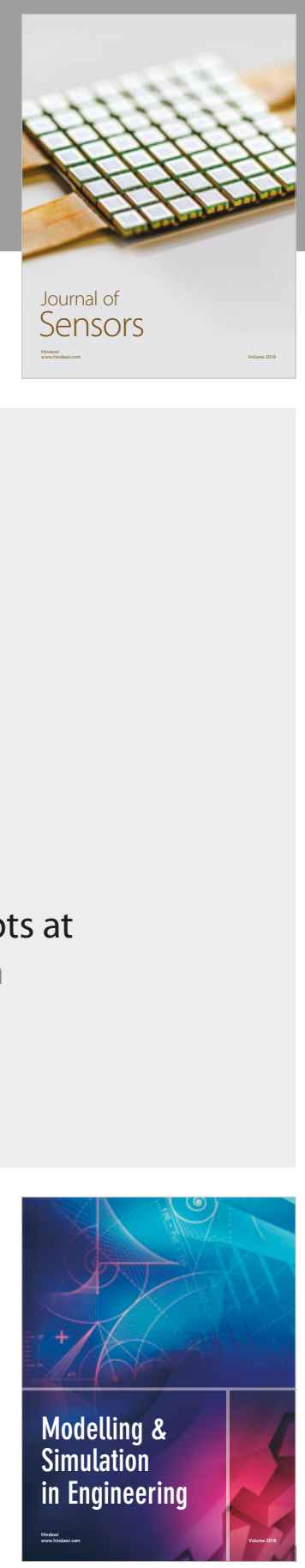

\section{Advances \\ Multimedia}
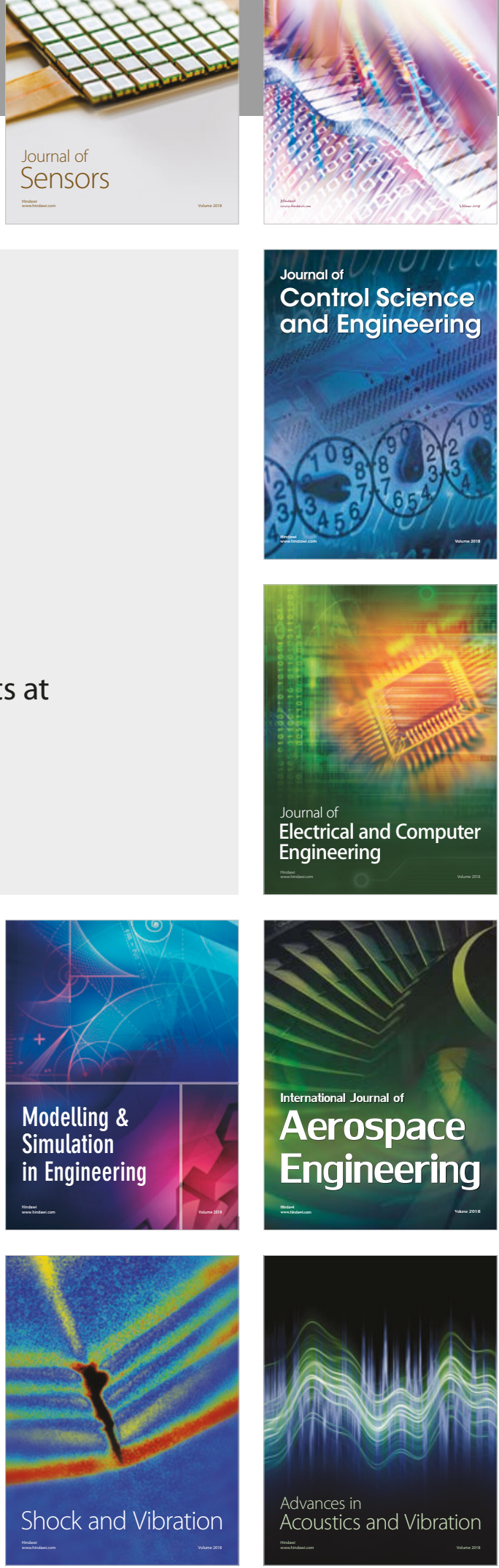